Helgoländer wiss. Meeresunters. 23, 193-231 (1972)

\title{
Beiträge zur Ökologie und Biologie von Blenniidae (Pisces) des Mittelmeeres
}

\author{
C. D. ZANDER \\ Zoologisches Institut und Zoologisches Museum der Universität Hamburg; \\ Hamburg, Bundesrepublik Deutschland
}

\begin{abstract}
Contributions to the ecology and biology of Blenniidae (Pisces) from the Mediterranean Sea. Twelve species of the fish genus Blennius (Blennioidei, Perciformes) have been investigated with regard to their ecological requirements at 20 distinct localities of the western and southern Mediterranean Sea. The species examined respond differently to the environmental factors temperature, light, salinity, and wave-action. Blennius cristatus is a thermophil species, whereas $B$. dalmatinus may be thermophobe. $B$. sanguinolentus, $B$. pavo, $B$. sphinx, and $B$. dalmatinus prefer habitats exposed to the sunlight; $B$. gattorugine and $B$. $z$ vonimiri inhabit shadow biotopes. One can find $B$. galerita, $B$. trigloides, and $B$. cristatus at the surf-stage normally, whereas $B . \operatorname{sphin} x, B$. canevae, and $B$. gattorugine are facultative inhabitants of this biotope. The vertical distribution depends on wave-action and, in part, on light. The main escape direction is upward to the water surface by most species inhabiting the surf-stage, downward by $B$, gattorugine and $B$. zvonimiri, and laterally by the other species examined. Morphological adaptations to the habitat in the surf-stage are indicated by the round or slightly depressed form of the body, and by the strong rays of the pectoral, pelvic and anal fins. None of the Blennius species examined exhibits ecological requirements similar to those of another species. It is probable that the striking specific radiation of the genus Blennius is rendered possible by the availability of different biotopes and microclimates.
\end{abstract}

\section{EINLEIT'UNG}

Die Familie Blenniidae ist im Mittelmeer durch die Gattung Blennius und Hypleurochilus bananensis Poll $(=H$. phrynus $\mathrm{BATH})$ vertreten. Diese Fische sind ausschließlich an Felssubstrat gebunden; die etwa 18 Blennius-Arten haben sich dort den verschiedensten Lebensräumen und Bedingungen angepaßt. Blernius ocellaris kommt $\mathrm{z}$. B. in Tiefen ab 30 Meter vor, während $B$. galerita und $B$. trigloides unmittelbar an der Wasserlinie gefunden werden; die meisten Arten leben allerdings im oberen Litoralbereich und sind daher ethologischen und ökologischen Untersuchungen leicht zugänglich.

Trotzdem gibt es bisher nicht allzu viele Berichte über die Biologie dieser Fische, die auf Beobachtungen im Biotop beruhen. EGGERT (1931) gab einige kurze Notizen über die Okologie und Lebensweise von 9 Blennius-Arten, während über B. galerita ron SoLJAN (1932) genaue Beobachtungen gemacht wurden. In seinen Studien über die 
Fische des Mittelmeeres widmete ABEL (1962) den Blenniidae ein größeres Interesse, indem er die vertikale Verbreitung sowie die Licht- und Wohnraumansprüche von $10 \mathrm{Ar}$ ten feststellte. Der gleiche Autor beschrieb 1964 die Einzelheiten des Fortpflanzungsverhaltens von $B$. canevae und $B$. inaequalis $(=B$. incognitus). Diese Arbeiten ABels sollen hier durch Berücksichtigung weiterer Arten und weiterer Umweltfaktoren ergänzt werden.

Für die taxonomische Einordnung von Formen werden jetzt in zunehmendem Maße nicht nur morphologische Merkmale, sondern das gesamte Spektrum der Eigentïmlichkeiten, die genetisch fixiert erscheinen, herangezogen. Die Erfassung ökologischer und biologischer Eigenschaften trägt wesentlich dazu bei, Artbildungsprozesse auch dann zu erkennen, wenn morphologische Methoden versagen. In dieser Arbeit soll die Bedeutung solcher Merkmale, die für die Evolution der Blenniidae eine Rolle gespielt haben, herausgestellt werden.

\section{MATERIAL UND METHODE}

Die biologischen und ökologischen Untersuchungen wurden 1968 auf einer Reise an die nordafrikanische und spanische Mittelmeerküste begonnen und während zweier Aufenthalte an der meeresbiologischen Station Banyuls-sur-Mer/Frankreich im Juli 1969 und 1970 vertieft. Ergänzt wurden diese durch Beobachtungen auf einer Reise im Mai 1971 nach Tarragona/Spanien und einem weiteren Aufenthalt im Oktober 1971 in Banyuls-sur-Mer sowie durch Tonbandprotokolle von Herrn U. von HACHT, die auf

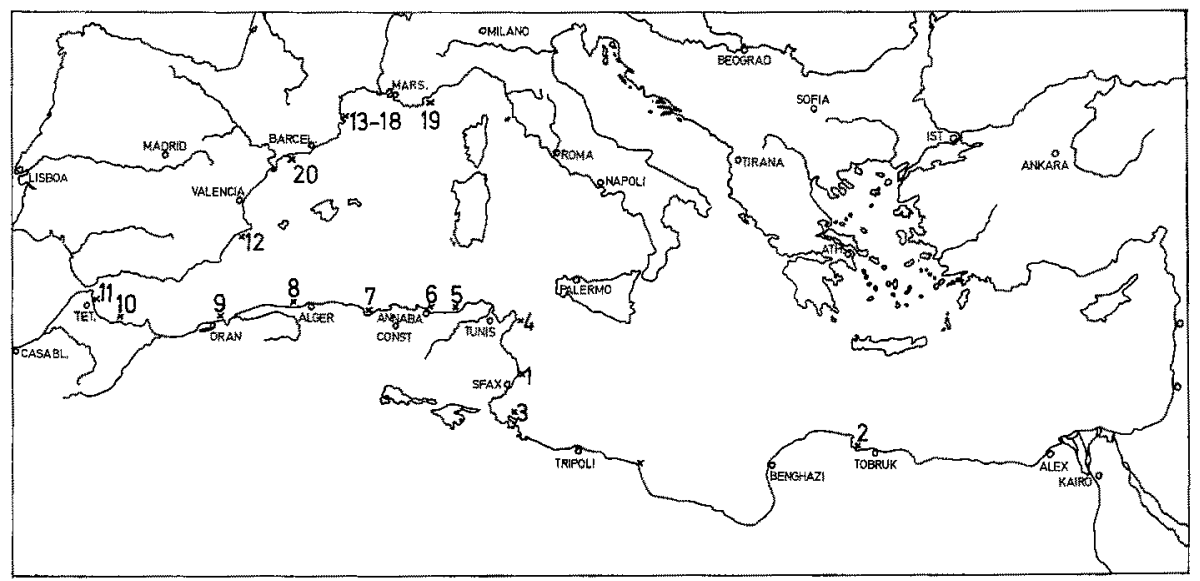

Abb. 1: Karte des Mittelmeeres mit den Fundstellen 1 bis 20, an denen Blennius-Arten beobachtet und gefangen wurden. Die Kennziffern der Stationen gelten für alle Abbildungen dieser Arbeit, 1 = Bei Salakta, S. Mahdia/Tunesien; $2=$ bei Ain Gazela, $78 \mathrm{~km}$ W Tobruk/Libyen; $3=$ Insel Dierba, $4 \mathrm{~km} \mathrm{~W} \mathrm{Houmt} \mathrm{Souk/Tunesien;} 4=$ Kelibia, Halbinsel Cap Bon/Tunesien; $s=$ bei Tabarka/Tunesien; $6=$ bei Annaba/Algerien; $7=$ Tichy, $16 \mathrm{~km}$ O Bejaia/Algerien; $8=$ Berard, $55 \mathrm{~km}$ SW Alger/Algerien; $9=$ bei Kristel, $16 \mathrm{~km}$ NO Oran/Algerien; $10=$ bei Al Hoceima $/$ Marokko; $11=$ Cabo Nero bei Mdiq, $14 \mathrm{~km}$ NO Tetouan $/$ Marokko; $12=$ Calpe, $60 \mathrm{~km}$ NO Alicante/Spanien; 13-18= Banyuls-sur-Mer, W Perpignan/Frankreich; $19=$ Dramont bei St. Raphael/Frankreich; $20=$ Tarragona/Spanien 
Grund von Untersuchungen in Dramont/Frankreich im August 1970 und 1971 entstanden sind. Die Lage der Untersuchungsstellen ist in Abbildung 1 dargestellt.

Die Beobachtungen wurden mit der Methode des Schwimmtauchens durchgeführt und beschränikten sich aus Zeitgründen meist auf den Bereich zwischen 0 und $1,5 \mathrm{~m}$ Wassertiefe. Nur in Banyuls-sur-Mer wurde zeitweilig tiefer, im Extremfall bis $10 \mathrm{~m}$ getaucht. Deshalb müssen hier die in tieferen Bereichen lebenden Arten Blennius rouxi und B. tentacularis unberüdssichtigt bleiben; $\mathrm{da}$, außer in Banyuls-sur-Mer und durch vON HACHT in Dramont, auch die Höhlenbiotope nicht näher untersucht werden konnten, muß damit gerechnet werden, daß z. B. B. nigriceps und $B$. zvonimiri an den nordafrikanischen Stationen übersehen wurden.

Etwa die Hälfte der untersuchten Stationen wird in der Strukturierung durch Photos und Profilzeichnungen beschrieben und ihre Blennius-Fauna genauer verzeichnet; ferner wird dort das Vorkommen der Blenniidae-Verwandten Tripterygion tripteronotus und T. xanthosoma aufgeführt, soweit dieses erfaßt wurde.

\section{ERGEBNISSE}

\section{Beschreibung der Biotope und Verteilung von Arten der Gattungen Blennits und Tripterygion}

Hier sollen 8 der untersuchten 20 Biotope genauer beschrieben und in Profilen dargestellt werden, da diese Auswahl ausreicht, die ökologischen Ansprüche der Blenniusund Tripterygion-Arten herauszustellen. Neben der Strukturierung und Zonierung wurde in diesen Profilen die Mittelwasserlinie (MWL) angegeben, oft auch eine Brandungs- (BWL) bzw. Sogwasserlinie (SWL). Tiden spielen im Mittelmeer keine Rolle und wurden daher nicht berücksichtigt. Die untersuchten Arten wurden in den Zeichnungen mit folgenden Symbolen gekennzeichnet: $C=$ Blennius cristatus $L$., $D=$ $B$. dalmatinus Steindachner \& Kolombatovic, $\mathrm{E}=B$. canevae Vinciguerra, $\mathrm{G}=$ $B$. gattorugine BrünNICH, $\mathrm{I}=B$. incognitus BATH, $\mathrm{M}=B$. galerita $\mathrm{L}$., $\mathrm{P}=B$. pavo Risso, $\mathrm{S}=B$. sanguinolentus Pallas, $\mathrm{T}=B$. trigloides Cuvier \& Valenciennes, $\mathrm{V}=B$. vandervekeni PolL, $\mathrm{X}=$ B. sphin $x$ Cuvier \& VAlencIennes, $\mathrm{Z}=$ B. zvonimiri Kolombatovic, $\mathrm{h}=$ Tripterygion xanthosoma Zander \& Heymer und $\mathrm{o}=$ T. tripteronotus (RIsso). Die Biotope werden mit den gleichen Ziffern bezeichnet, die schon in Abbildung 1 für die geographische Lage verwendet wurden.

Station 2: Felsterrasse mit Höhle bei Ain Gazela/Libyen. 12. 8. 1968. Leichte Brandung, Luft $46^{\circ}$, Wasser $28^{\circ} \mathrm{C}$ (Abb. $2 / 2$ und 4).

Die Untersuchungsstelle liegt an einem Einschnitt des steilen Felsufers, der mit Sand ausgefüllt ist. Das Gestein ist stark zerklüftet; es sind dort sehr viele Hohlkehlen und $z$. T. auch Brückenbildungen mit darunterliegenden Höhlen anzutreffen (Abb. 2/2). Durch eine solche Höhle, die von 2 Seiten her zugänglich ist, wurde das Profil 2 gelegt und dadurch alle dort vorkommenden Blennius- und Tripterygion-Arten erfaßt (Abb. 4).

Landseitig beginnt der unter der Wasserlinie liegende Teil in der erwähnten Höhle, die ca. $1,5 \mathrm{~m}$ breit ist und eine Wassertiefe von $30 \mathrm{~cm}$ besitzt. Hier wurde Blennius 

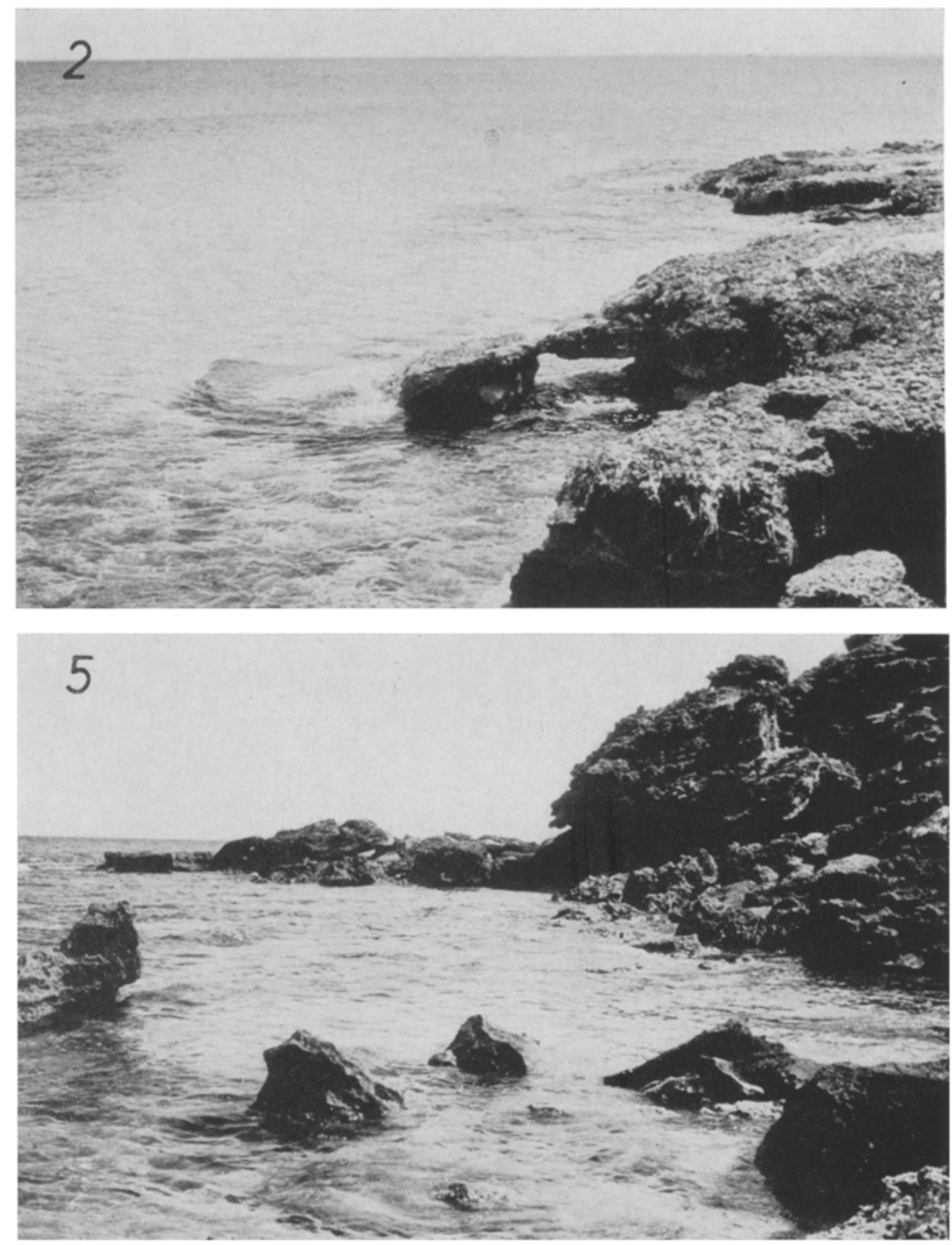

Abb. 2: Strukturierung der genauer beschriebenen Fundstellen: $2=$ Ain Gazela, $5=$ Tabarka

canevae und bezeichnenderweise auch der schattenliebende Tripterygion xanthosoma gefunden (ZANDER \& HEYMER 1970). Von der Höhlung durch eine Gesteinsbrücke getrennt folgt eine fast horizontal liegende Felsterrasse, die höchstens $20 \mathrm{~cm}$ unter der MWL liegt. Diese war mit Cystoseira und Enteromorpha sehr dicht bewachsen; zwischen diesen Algen war Blennius sphinx sehr häufig. Ca. $3 \mathrm{~m}$ vom Uferrand entfernt 

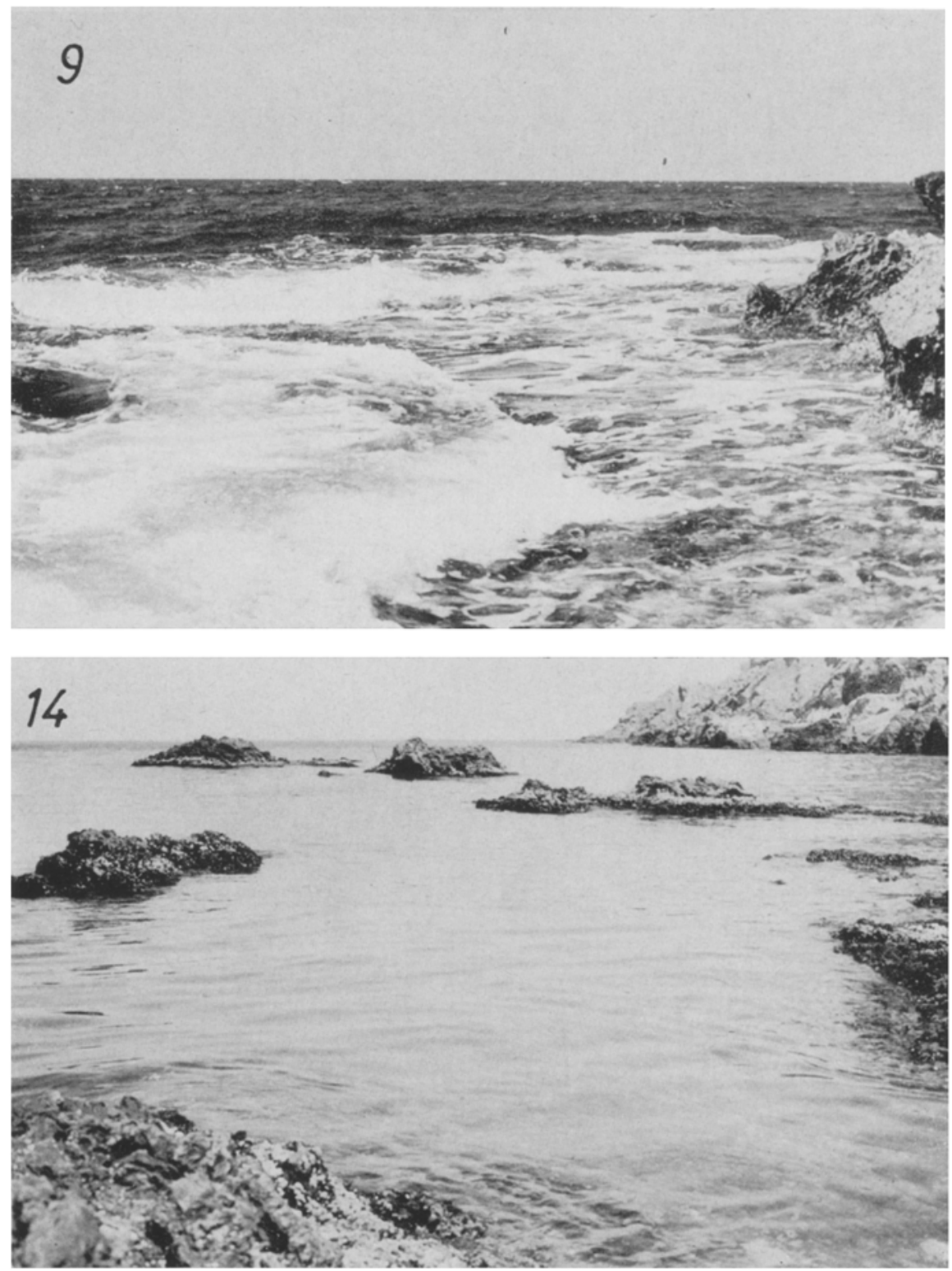

Abb. 3: Strukturierung der genauer beschriebenen Fundstellen: $9=$ Kristel, $14=$ Banyulssur-Mer

fällt die Felsterrasse steil auf $80 \mathrm{~cm}$ unter die MWL ab, um sich in eine weitere schmale Terrasse fortzusetzen. An dem Felsabfall dominierte Padina-Bewuchs, seltener war Halimeda; dort war nur Tripterygion tripteronotus anzutreffen, der "hüpfend“ von Mulde zu Mulde schwamm. Die Laichzeit dieser Tiere war offensichtlich schon beendet, 
da keine $\hat{O} \delta$ in der sonst auffallend schwarz-roten Fortpllanzungstracht zu finden waren. Auf der tiefliegenden Felsterrasse mit Cystoseira-Bewuchs waren einige $B$. incognitus anzutreffen; die $\hat{O} \delta$ dieser Art zeigten hier auffallend lange Orbitaltentakel und deutliche Drüsenanhänge an den beiden ersten Analis-Strahlen, sie waren demnach noch in Fortpflanzungsstimmung. Allerdings waren keine $\hat{\delta} \hat{o}$ mehr in Löchern

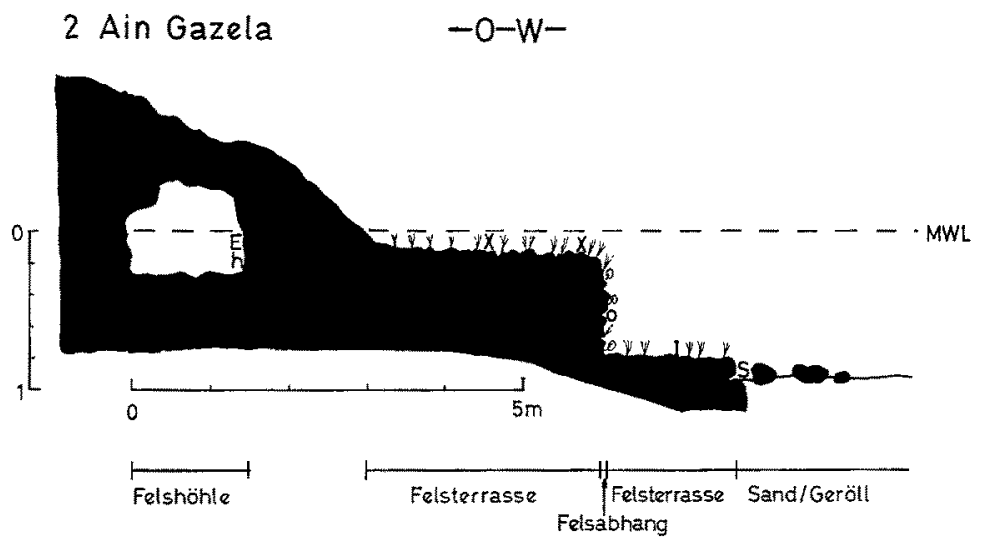

Abb. 4: Schematisches Profil der Fundstelle 2 mit den Habitaten der Blennius- und Tripterygion-Arten. Erklärung der Symbole auf p. 195. MWL: Mittelwasserlinie

anzutreffen. Die tiefe horizontale Terrasse geht mit einem kurzen Absatz in eine Sandzone über, in die einige abgeschliffene Gesteinstrümmer eingelagert sind. An der Grenze dieser beiden Zonen wurde $B$. sanguinolentus gesehen, der sich zwischen dem kleinen Geröll aufhielt und sich bei Störung blitzschnell darunter versteckte.

Station 4: Felsabfall mit Terrasse und Geröllstrand bei Kelibia/Tunesien. 23. 8. 1968. Morgens mäßige Brandung, mittags stärker werdend, so daß die herausragenden Felsen überspült wurden. Luft $35^{\circ}$, Wasser $26^{\circ} \mathrm{C}$ (mittags) (Abb. 5).

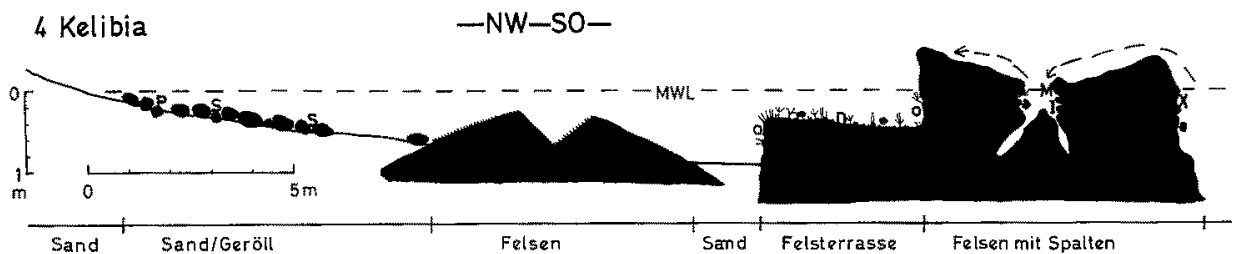

Abb. 5: Schematisches Profil der Fundstelle 4 mit den Habitaten der Blennius- und Tripterygion-Arten. Erklärung der Symbole auf p. 195. MWL: Mittelwasserlinie

Im Nordosten der tunesischen Halbinsel Kap Bon befindet sich bei dem alten Fort von Kelibia eine Felsküste, die sich mit starker Neigung 2-3 $\mathrm{m}$ aus dem Wasser erhebt. An einigen Stellen weicht der Fels zurück und läßt dort mit Sand aufgefüllte Buchten entstehen.

Das Profil 4 wurde an einer solchen Sandaufschwemmung begonnen (Abb. 5). Von 
der MWL an ist diese Sandzone in einer Länge von $6 \mathrm{~m}$ mit Kleingeröll bedeckt und neigt sich in diesem Bereich bis in ca. $50 \mathrm{~cm}$ Tiefe. Sehr nahe am Ufer lebte hier zwischen dem Gestein B. pavo, während im tieferen Bereich dieser Zone B. sanguinolentus anzutreffen war. Dominierend war dort allerdings ein Fisch aus einer anderen taxonomischen Gruppe: Gobius bucchichi. Die Sand-Geröll-Zone endet bei 2 Geröllquadern, deren Oberkante bis $25 \mathrm{~cm}$ an die MWL heranreicht. Diese sind sehr abgeschliffen und wiesen einen feinen Grünalgenbelag auf; Blenniiden waren hier nicht vertreten. Getrennt durch eine schmale Sandzone schließt sich eine Felsterrasse an, die sich bis in $25 \mathrm{~cm}$ Tiefe erhebt. Sie war vor allem mit Cystoseira und Padina bewachsen. Auf dem Plateau hielt sich $B$. dalmatinus auf, der zwischen den Pflanzen herumschwamm. An den landwärts gerichteten Felshängen wurde T. tripteronotus gefunden. Diese Wände lagen zur Untersuchungszeit im Schatten. Seeseitig schließen sich 2 über die MWL reichende Felsblödke an, zwischen denen eine enge Spalte von $60 \mathrm{~cm}$ besteht, die nach unten zu immer schmäler wird. Am freien Wasser fällt der Felsen steil in die Tiefe ab. Als Bewuchs war dort nur Chaetomorpha und Padina zu finden; an und tiber der Wasserlinie lebte Chbthalamus und die Gastropoden Patella und Gibbula; in der Felsspalte dominierte Paracentrotus lividus. Von Blenniidae waren zwischen den beiden Felsen B. galerita, der sich meist U-förmig in Mulden an der Wasserlinie preßte, und B. incognitus in Löchern $30 \mathrm{~cm}$ unter der Oberfläche zu finden. An der Außenseite des am weitesten seeseitig gelegenen Felsens hielten sich der vollen Brandung ausgesetzt Exemplare von B. spbinx nahe der Wasserlinie frei auf dem Felsen auf.

$\mathrm{S}$ t a t i on 5: Felskap bei Tabarka/Tunesien mit Geröll- und Sandstrand. 27. 8. 1968. Wassertemperatur $25^{\circ}$, im flachen Bereich $26^{\circ} \mathrm{C}$ (mittags). Vormittags leichte Brandung, nachmittags durch aufkommenden Wind stärker, so daß einige über die MWL herausragende Felsen überspült wurden (Abb. 2/5 und 6).

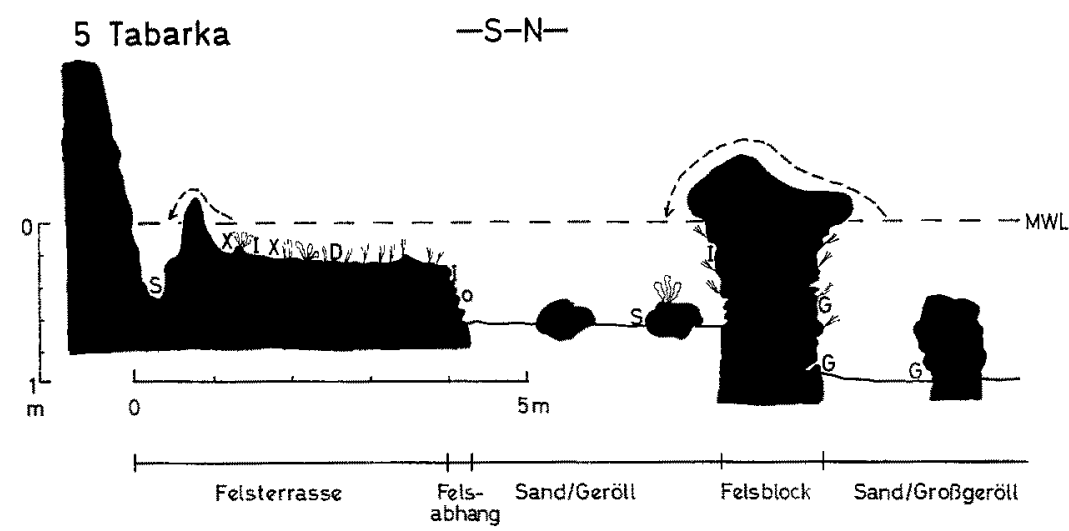

Abb. 6: Schematisches Profil der Fundstelle 5 mit den Habitaten der Blennius- und Tripterygion-Arten. Erklärung der Symbole auf p. 195. MWL: Mittelwasserlinie

$3 \mathrm{~km}$ östlich von Tabarka wird der breite Sandstrand durch ein kleineres vorgelagertes Felskap durchbrochen, dem viele Geröllblödke vorgelagert sind (Abb. 2/5). Das Profil 5 (Abb. 6) beginnt mit einem steilen Felsabfall, der bis $60 \mathrm{~cm}$ unter die Was- 
serlinie führt und kurz danach wieder über diese ansteigt. Dadurch wird eine grabenartige Vertiefung gebildet, an derem Grund $B$. sanguinolentus anzutreffen waren; diese Fische flohen bei Störung in Felsspalten. An den Graben schließt sich eine ausgedehnte Felssterrasse an, 20 bis $30 \mathrm{~cm}$ unter der Oberfläche gelegen. Dieses Plateau war dicht mit Ulva, Enteromorpha und Cystoseira, ab und zu auch mit Halimeda bewachsen. Hier war B. spbinx sehr häufig und auch B. dalmatinus. Im unteren Bereich der Felsterrasse, in dem Cystoseira-Bewuchs vorherrscht, und an dem folgenden, bis in $60 \mathrm{~cm}$ Tiefe reichenden Felsabfall wurde $B$. incognitus angetroffen. An dieser Stelle, die - nordexponiert - im Schatten liegt, lebte auch T. tripteronotus. Es folgt eine Sandzone, auf der einige größere Gesteinstrümmer liegen, die mit Ulva bewachsen sein können. Am Fuß dieses Gesteins kam B. sanguinolentus vor. Die Sandzone wird durch einen über die MWL herausragenden Felsblock unterbrochen, der mit wenig Cystoseira bzw. an der Schattenseite mit Halopteris bewachsen war und den Gastropoden Patella und Gibbula Lebensraum gab. Er ist durch Löcher, Spalten und Mulden stark aufgegliedert, seine seewärts gelegene Wand reicht weiter als $1 \mathrm{~m}$ in die Tiefe. An dieser Wand lebte auch B. gatiorugine, wobei adulte Exemplare am Fuß des Felsens, Jungtiere aber in höheren Bereichen vorkamen; an der landwärts gerichteten Seite dieses Felsens lebte vereinzelt $B$. incognitus. Die weitere Gliederung dieses Fundortes ist durch steil aufragende Felsen mit dazwischen verlaufenden Sandgräben charakterisiert.

Station 7: Felsinsel vor dem Sandstrand von Tichy/Algerien. 2.9.1968. Trotz ruhiger Wetterlage starke Brandung. Temperatur Luft $29^{\circ}$, Wasser $25^{\circ} \mathrm{C}$ (vormittags) (Abb. 7).

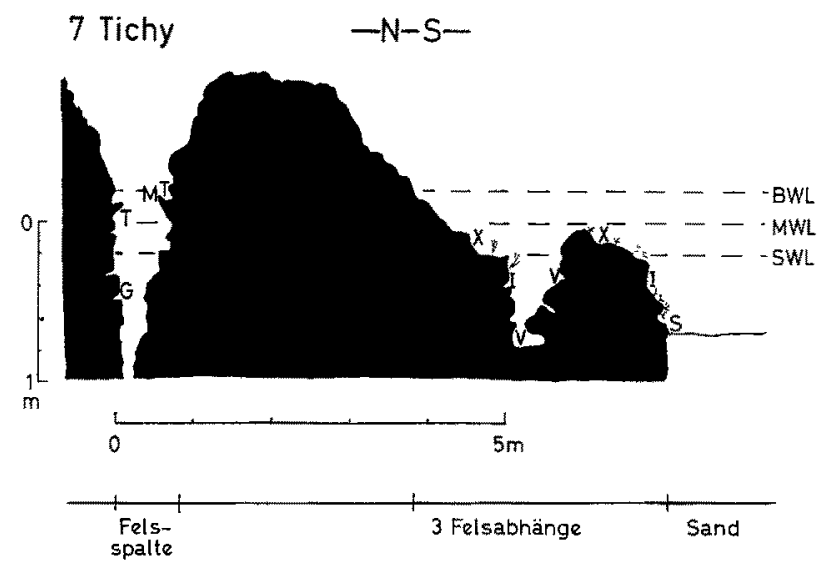

Abb. 7: Schematisches Profil der Fundstelle 7 mit den Habitaten der Blennius-Arten. Erklärung der Symbole auf p. 195. BWL, MWL und SWL: Brandungs-, Mittel- und Sogwasserlinie

Etwa 50 bis $60 \mathrm{~m}$ vom Badestrand von Tichy entfernt erhebt sich aus dem flachen Sandgrund ein Komplex mehrerer Felsklippen, der $2 \mathrm{~m}$ und mehr über die Wasseroberfläche herausragt. Diese Felsen sind sehr strukturiert und fallen unter Wasser meist steil ab. Die $Z$ wischenräume und Spalten zwischen den Felsen reichen weiter in die Tiefe als der umgebende Sandgrund. Das Profil 7 (Abb. 7) beginnt mit einer Spalte 
zweier weit über die MWL ragender Felsen, die weitgehend im Schatten liegt. Im Supralitoral und Brandungsbereich sind Chthamalus und die Gastropoden Patella und Gibbula zu finden; Algenbewuchs war nicht vorhanden. Dort finden 3 Blennius-Arten ihren Lebenstaum: B. galerita, B. trigloides und B. gattorugine. B. galerita lag in Mulden an der Wasserlinie oder sogar darüber, so daß er dann nur von den Brandungswellen benetzt wurde. $B$. trigloides besetzte im Prinzip den gleichen Lebensraum; er wurde in Brandungsbereich in kleinen wannenartigen Vertiefungen gesehen, die nach Ablauf der Wellen mit Wasser gefüllt bleiben oder dieses nur geringfügig abfließen ließen. Diese sehr scheuen Fische flohen bei Störung sofort. B. gattorugine war erst ab $30 \mathrm{~cm}$ und tiefer unter der MWL zu finden. Diese Art saß meist auf dem freien Felsen und floh bei Annäherung in optische Höhlen (sensu ABEL 1959). Auf die eben beschriebene enge Spalte folgt in etwa $5 \mathrm{~m}$ Abstand eine schmale Terrasse des sich absenkenden Felsens, die danach steil in einen $80 \mathrm{~cm}$ tiefen Graben abfällt. Die gegenüberliegende Wand dieses Grabens steigt steil bis fast an die MWL an und bildet durch erneute $\mathrm{Ab}$ senkung einen Buckel; der letzte Abfall reicht bis $60 \mathrm{~cm}$ Tiefe zu einem Sandgrund, der bis zum Badestrand von Tichy langsam ansteigt. Die Felsterrasse sowie der Felsbuckel und die der Sonne ausgesetzten Felsabfälle waren mit feinen Grünalgen, Corallina und wenig Padina bewachsen, während an der schattigen Seite des Grabens Algen fehlten. Auf der besonnten Felsterrasse und dem Felsbuckel waren B. sphinx sehr häufig, die $z$ wischen den Algen nach Futter suchten. Bei starkem Sog blieben sie eine kurze Zeit auf dem trockenen Gestein zurück. In etwas tieferen Zonen, aber ebenfalls in besonnten Habitaten mit Algenbewuchs hielt sich $B$. incognitus auf. $B$. vandervekeni bevorzugte dagegen die schattenexponierten, unbewachsenen Wände, an der Jungfische $a b 30 \mathrm{~cm}$, Adulte ab $50 \mathrm{~cm}$ unter der MWL angetroffen wurden. Ihren Versteckplatz bildeten Spalten und größere Löcher im Gestein. An der Grenze Fels-Sand-Untergrund lebte $B$. sanguinolentus, der auch an einzelnen Felsen im Sanduntergrund zum Ufer hin vorkam.

Station 9: Steile Felsklippen bei Kristel/Algerien. 6. 9. 1968. Starke Brandung. Wassertemperatur $24-25^{\circ} \mathrm{C}$ (vormittags) (Abb. 3/9 und 8).

Es handelt sich hier um ein zerklïftetes Felsufer, das aus etwa $5 \mathrm{~m}$ Höhe steil ins Wasser abfällt. Dazwischen gibt es tiefe canyonartige Einschnitte von unterschiedlicher Breite. An der Wasseroberfläche sind oft breite Plateaus ausgebildet (Abb.3/9), die unter dieser steil bis etwa $10 \mathrm{~m}$ Tiefe abfallen, evtl. aber auch Zwischenplateaus bilden. In den Canyons sind überhängende Felspartien sehr häufig zu finden.

Im Profil 9 (Abb. 8) wird ein Steilabfall dargestellt, der $35 \mathrm{~cm}$ unter der MWL in eine breite Terrasse übergeht. Diese Terrasse liegt noch im Einflußbereich der Brandungswellen, so daß sie während der Sogwirkung kurzzeitig trocken fällt. Das Supralitoral war in der Spritzzone mit Chthamalus besetzt, der aber von der Brandungszone an abwärts fehlte; auf dem steilen, nackten Felsen hielten sich dort Chiton, Patella, Gibbula und Littorina neritoides auf. Erst auf der ca. $3 \mathrm{~m}$ breiten horizontalen Felsterrasse trat Algenbewuchs auf: zum Felsabfall hin Padina, im übrigen Abschnitt dagegen besonders Cystoseira und Corallina, aber wenig Cladophora. Auf dieser Felsterrasse waren 4 Blennius-Arten vertreten: $B$. sphinx wurde überall auf dem Plateau, soweit es in der Sonne lag, gefunden. Ebenso häufig war B. cristatus, der sich in Felsvertiefungen preßte oder $\mathrm{zwischen}$ Algen verharrte. An der Kante zum folgenden Ab- 
hang waren außer den beiden erwähnten Arten B. galerita und B. trigloides in größerer Anzahl vertreten. Während sich Exemplare letzterer Art in Mulden drückten, lag B. galerita frei auf dem Felsen. Die folgende, bis auf $1 \mathrm{~m}$ Tiefe abfallende Felswand wies nicht an allen Stellen Algenbewuchs (ausschließlich Corallina) auf. Dominierend war hier Paracentrotus lividus. An dieser Wand war B. canevae bis fast zur oberen

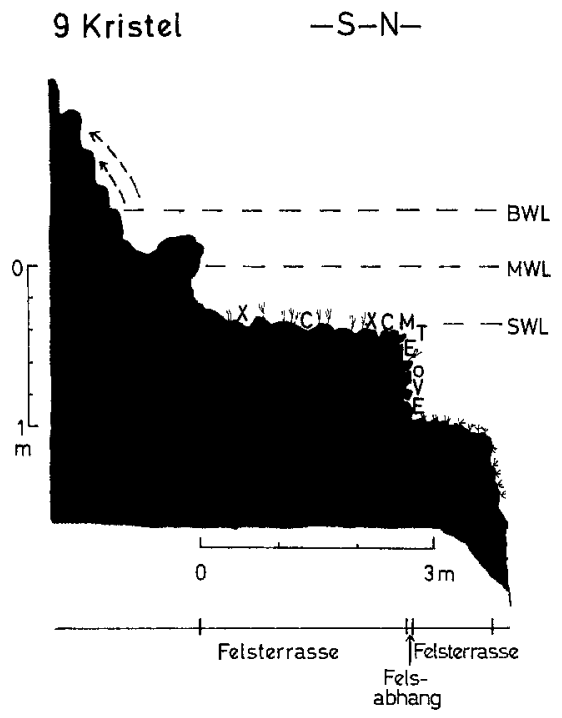

Abb. 8: Schematisches Profil der Fundstelle 9 mit den Habitaten der Blennius- und Tripterygion-Arten. Erklärung der Symbole auf p. 195. BWL, MWL und SWL: Brandungs-, Mittelund Sogwasserlinie

Kante vertreten sowie $B$. vandervekeni in seinem tieferen Abschnitt zwischen dichten Corallina-Polstern und auch $T$. tripteronotus. In etwa $1 \mathrm{~m}$ Tiefe folgt noch einmal eine schmale Felsterrasse, ehe die Wand bis auf etwa $7 \mathrm{~m}$ steil auf einen Sandgrund abfällt. Dort wurden keine Blennius- oder Tripterygion-Arten während der Untersuchungszeit mehr entdeckt. Hervorzuheben ist, daß dieser Biotop vollkommen ungeschützt dem offenen Meer zugewendet liegt.

St a t i o n 11: Fels-Geröll-Strand in einer Felsbucht bei Mdiq/Marokko. 10.9. 1968. Starke Brandung, Wasser leicht getrübt, Wassertemperatur $20^{\circ} \mathrm{C}$ (vormittags) (Abb. 9).

Ca. $10 \mathrm{~km}$ nördlich der marokkanischen Stadt Tetouan erhebt sich das weit ins Meer vorspringende Cabo Nero. Die Untersuchungsstelle liegt an seiner Nordseite in einer Bucht, die von hohen Felsen umschlossen ist. Der Untergrund ist mit Gesteinstrümmern und Kleingeröll jeder Größe belegt. Die Felsen zeigen wenig Strukturierung; sie fallen meist steil ins Wasser $a b$ und bilden $z$. T. Hohlkehlen an der MWL aus.

Das Profil 11 (Abb. 9) verläuft vom Ufer aus über 3 wannenartige Vertiefungen unterschiedlicher Tiefe und Breite bis zu einer etwa $7 \mathrm{~m}$ entfernten, über die MWL ragende Felskuppe. Der Boden dieser Wannen ist mit kleinen Gesteinstrümmern ausgefüllt, die mit feinen Grünalgen bewachsen waren. An den Wänden wuchsen relativ 
wenig Algen, unter denen noch die Rotalgen Corallina und Sphaerococcus vorherrschten und Ulva und Enteromorpha nur selten zu finden waren. Der im Profil gezeichnete letzte Felsabfall vor der Kuppe war bis auf etwas Ulva nackt. Uber der MWL wurde Cbtbalamus und Patella gefunden; an den kahlen Felsen waren Paracentrotus-Seeigel häufig.

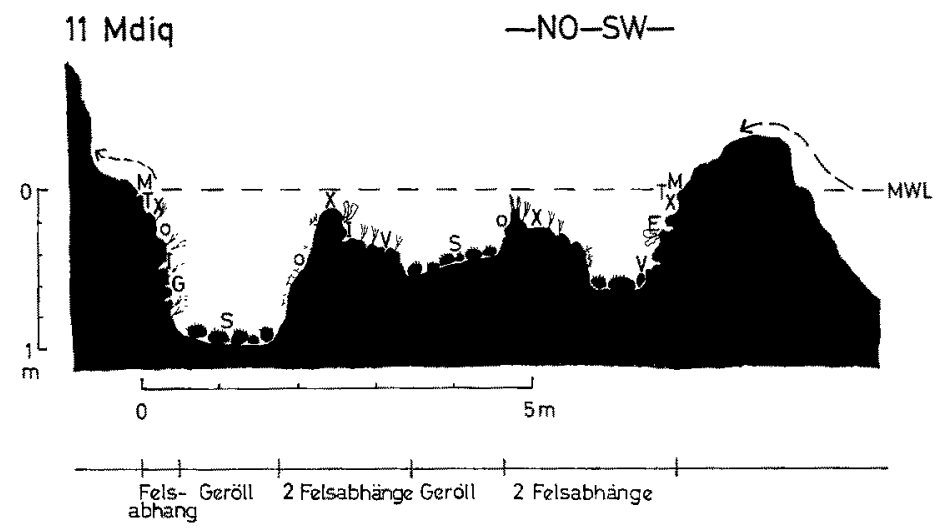

Abb. 9: Schematisches Profil der Fundstelle 11 mit den Habitaten der Blennius- und Triptery gion-Arten. Erklärung der Symbole auf p. 195. MWL: Mittelwasserlinie

Von Blenniidae waren hier 8 Arten vertreten, ferner noch $T$. tripteronotus. $B . g a-$ lerita kam direkt an der Wasseroberfläche sowohl in besonnten als auch in schattigen Habiaten vor. Die Tiere saßen oft in kreisförmigen Vertiefungen des Gesteins von 4-5 cm Durchmesser. An den gleichen Stellen wurde auch B. trigloides gefunden, der sich aber in Spalten und Mulden versteckte. B. sphinx wurde dagegen auf den wasserbedeckten Kuppen angetroffen, die ständig dem Sonnenlicht ausgesetzt sind. Hier schwammen sie frei umher und verbargen sich bei Störung zwischen den Algen. In den Bohrmuschellöchern oder in Mulden der schattigen Wand war B. canevae zu finden. An der direkt am Ufer absteigenden Wand schwamm $B$. gattorugine in einer Tiefe von $50-100 \mathrm{~cm}$ umher. An diesem Abhang war auch B. incognitus vertreten, der sich in Löchern oder zwischen den Sphaerococcus-Thalli verbarg. An solchen Stellen, an denen die Felswände in die geröllbelegten Felsgründe übergehen, wurde $B$. vandervekeni angetroffen; zwischen dem Geröll lebte $B$. sanguinolentus, der bei Störung unter diesem verschwand. Durchweg an allen Wänden wurde T. tripteronotus gefunden.

$\mathrm{St}$ a t io n 12: Badestrand von Calpe/Spanien mit Felsufer. 12.9. 1968. Wasser $25^{\circ} \mathrm{C}$ (mittags). Mittags leichte Brandung, die abends durch einen Sturm erheblich verstärkt wurde (Abb. 10).

Dieser Badestrand wird seitlich von flachen, reich strukturierten Felsen begrenzt, die höchstens $2 \mathrm{~m}$ über die Wasserlinie ansteigen und unter dieser auf einen flachen Sandgrund abfallen. Das Profil 12a (Abb. 10) weist in Nord-Süd-Richtung und beginnt über der Wasserlinie mit einem Spritzwassertïmpel, der mit Chtbalamus, Chiton und Patella besetzt war. Die vordere Kante dieses Tümpels fällt auf eine fast horizontale Felsterrasse $a b$, deren größter Teil $20 \mathrm{~cm}$ unter der MWL im Bereich der ablaufenden Wellen liegt und daher kurzzeitig trockenfällt. Am Beginn wies dieses Plateau nur 
einen Bewuchs von feinen Grünalgen auf, in seinem weiteren Verlauf waren aber auch Braun- und Rotalgen, vor allem Corallina und Sphaerococcus, weniger häufig Cystoseira zu finden. 'Zwischen diesen Pflanzen war $B$. spbinx sehr zahlreich und B. canevae etwas seltener zu finden. Beide Arten lagen bei Ablaufen der Brandungswellen auf dem trockenen Gestein. B. canevae versteckte sich bei Störung zwischen den Algen oder in Löchern. Vor dem eigentlichen Abfall der Felsterrasse wird diese von einer $1 \mathrm{~m}$ breiten, grabenartigen Vertiefung durchschnitten. An der Kante dieser Absenkung wurde $B$. trigloides und seltener $B$. cristatus gefunden. Während ersterer zwischen den Algen oder in Mulden liegend beobachtet wurde, verbarg sich $B$. cristatus in Löchern und floh, aus
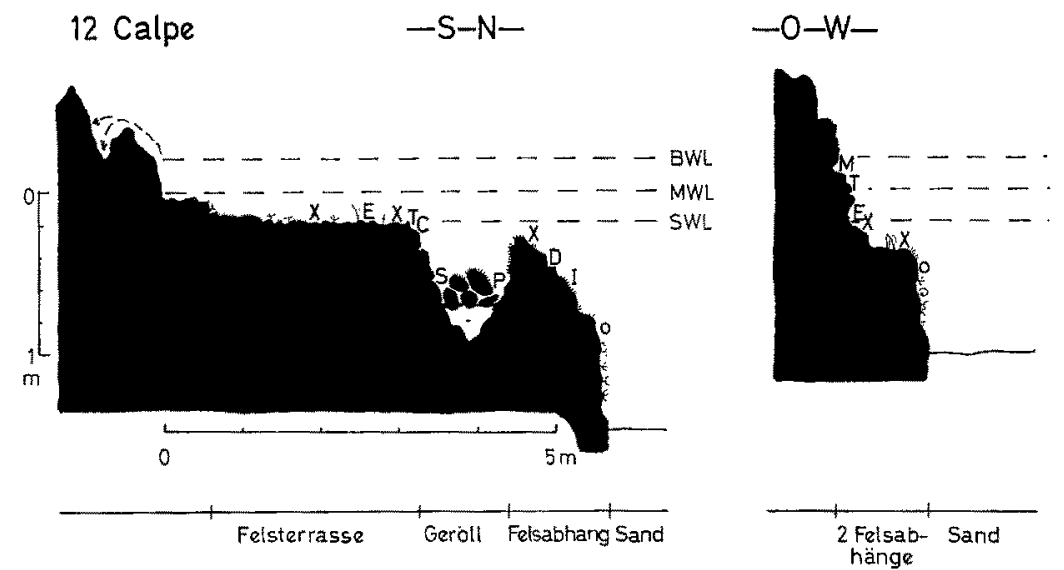

Abb. 10: 2 schematische Profile der Fundstelle 12 mit den Habitaten der Blennitus- und Tripterygion-Arten. Erklärung der Symbole auf p. 195. BWL, MWL und SWL: Brandungs-, Mittelund Sogwasserlinie

diesen vertrieben, auf das Plateau zwischen die Corallina-Thalli. Unterhalb des Brandungswellenbereiches hielt sich dagegen $B$. incognitus an der Wand des Einschnittes in etwa $40 \mathrm{~cm}$ Tiefe auf. Der Graben selbst ist am Grund mit Sand ausgefüllt, auf dem mit feinen Grünalgen bewachsene Gesteinstrümmer lagern. Zwischen diesen hielten sich $B$. sanguinolentus und B. pavo auf. Auf den Graben folgt eine stark geneigte Wand, die ab $70 \mathrm{~cm}$ unter der Wasseroberfläche auf den Sandgrund der Bucht abfällt. An seiner Kante, die außerhalb des Bereiches der ablaufenden Brandungswellen liegt, war B. spbinx auf dem feinen Grünalgenbewuchs des Gesteins zu finden. Etwas tiefer kamen $B$. dalmatinus und $B$. incognitus vor. An der senkrechten, mit Corallina bewachsenen Wand war nur noch $T$, tripteronotus anzutreffen.

In dem Profil 12b (Abb. 10), das einen Schnitt des Ufers in West-Ost-Richtung zeigt, ist der Einfluß der Brandungswellen auf eine mehr oder weniger steile Felswand beschränkt; ein sehr schmales Plateau liegt etwa $40 \mathrm{~cm}$ unter der MWL. Hier sind daher auch andere Verhältnisse als im Profil 12a zu finden. An dem kahlen, weißen Gestein lebte $B$. galerita so hoch über der MWL, daß er in Mulden sitzend nur selten von Wellen überspült wurde. Direkt an der MWL wurde manchmal noch $B$. trigloides gesehen, während etwas tiefer sich $B$. canevae und $B . \operatorname{sphinx}$ aufhielten. An dem folgen- 
den steilen Felsabhang, der mit Corallina und wenig Padina bewachsen war, wurde, wie im Profil 12a, nur' $T$. tripteronotus beobachtet.

$S$ tation 14: Klcine Insel am Felsufer von Banyuls-sur-Mer/Frankreich. 1.-6. 7. 1969. Wassertemperatur $18-19^{\circ} \mathrm{C}$ (Abb. 3/14 und 11).

An dem steilen, ungefähr $20 \mathrm{~m}$ hohen Felsufer direkt am Laboratoire Arago in Banyuls ragen mehrere kleine Inseln über die Wasseroberfläche, die dicht mit Miesmuscheln besetzt sind (Abb. 3/14). Von einer dieser Inseln, die nur $3 \mathrm{~m}$ vom Ufer entfernt liegt, wurde das Profil 14 bis in eine Tiefe von $2 \mathrm{~m}$ gezeichnet (Abb. 11). Vom

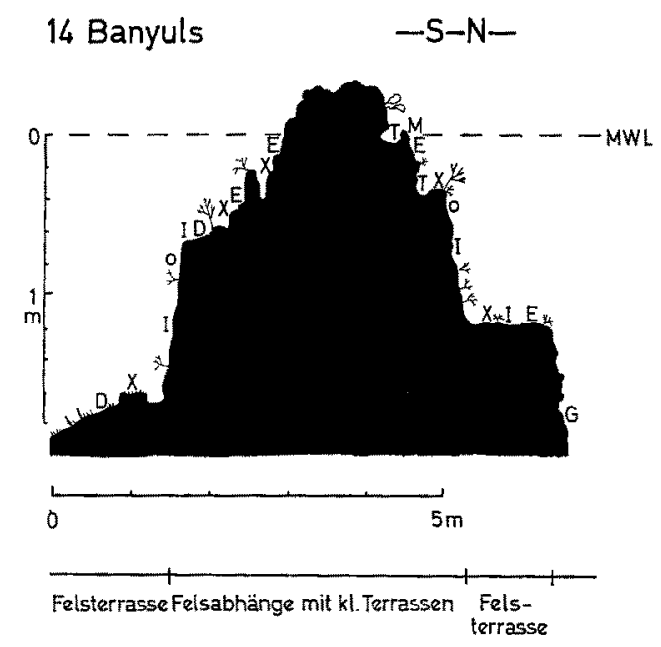

Abb. 11: Schematisches Profil der Fundstelle 14 mit den Habitaten der Blennius- und Tripterygion-Arten. Erklärung der Symbole auf p. 195. MWL: Mittelwasserlinie

Land ist diese Insel durch einen $2 \mathrm{~m}$ tiefen Graben getrennt, zur See fällt sie über $5 \mathrm{~m}$ in einen Sandgrund $a b$; da diese Seite nach Norden gerichtet ist und keine weiteren Inseln vorgelagert sind, ist sie während der in Banyuls häufig auftretenden Nordstürme der Kraft der mehrere Meter hohen Brandung ausgesetzt. Die Kuppe der langgestreckten Insel ragt etwa $30 \mathrm{~cm}$ über die MWL und war außer an der Spitze mit Mytilus, Corallina und vereinzelt mit Ulva bewachsen. Dort wurden auch die Gastropoden Patella und Monodonta sowie die Assel Ligia angetroffen. An der seewärts gelegenen

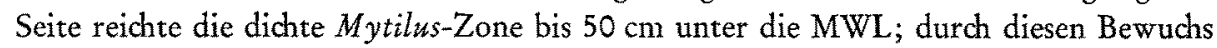
war das Substrat stark strukturiert und ließ Wannen, Mulden und Höhlungen entstehen. Zwischen den Muscheln wuchsen auf dem Gestein die Algen Corallina, Codium dichotomum, vereinzelt auch Ulva und Cystoseira. An Wirbellosen waren hier am häufigsten Anemona sulcata, über denen Leptomysis-Schwärme schwebten, und Paracentrotus lividus. Von Blenniiden wurde diese Zone eindeutig durch B. trigloides beherrscht. Von dieser Art waren über $10 \mathrm{~cm}$ große Exemplare überall zwischen den Vertiefungen des Substrats zu finden, besonders häufig im Bereich der Brandungswellen, wo die Tiere dann auf dem trodkengefallenen Gestein lagen. Dagegen waren andere Arten nur als Gäste dieses Bereichs anzusehen, z. B. B. galerita, der ebenfalls in einzel- 
nen Exemplaren an der MWL angetroffen wurde, B. sphinx und B. canevae. Nur wevig häufiger sind die beiden letztgenannten Arten in der nun folgenden Zone, deren Gestein nicht mehr mit Mytilus bewachsen, sondern von Diatomeen überzogen war. Es handelt sich um einen in $120 \mathrm{~cm}$ Tiefe reichenden Felsabfall, der sich dort in ein schmales Plateau fortsetzt. An Großalgen waren dort nur vereinzelt Thalli von Codium dichotomum und Corallina zu finden. Außer $B . \operatorname{sphinx}$ und $B$. canevae, die besonders auf der horizontalen Terrasse angetroffen wurden, konnte hier noch $B$. incognitus und $T$. tripteronotus an der steilen Wand festgestellt werden. Der auf das Plateau folgende Abhang reicht bis in $5 \mathrm{~m}$ Tiefe. Er wies keinerlei Bewuchs mehr auf und war auch wenig strukturiert. Selten wurde dort B. gattorugine beobachtet. An der anderen - landwärts gerichteten Seite erstreckte sich die dicht mit Mytilus bewachsene Zone nur bis $20 \mathrm{~cm}$ unter die MWL. Hier hielten sich höchstens vereinzelt $B$. canevae- +9 oder $B . \operatorname{sphinx}$ herumstreifend auf. An der folgenden, schräg abfallenden Wand, die in eine schmale Terrasse ausläuft, war Mytilus selten, dafür Anemona sulcata bäufiger; an Bewuchs wurde vereinzelt Codium und Cystoseira angetroffen. In diesem Bereich waren $B$. spbinx und $B$. canevae sehr zahlreich und auch $B$. incognitus und $B$. dalmatinus anzutreffen. Es folgt eine bis in $160 \mathrm{~cm}$ Tiefe reichende steile Felswand, die mit einem feinen Grünalgenbelag versehen war und auf der nur wenige Büschel Codium und $C y$ stoseira wuchsen. Hier waren nur $B$. incognitus und $T$. tripteronotus zu beobachten. Am Fuße dieses Abhanges folgt eine wenig geneigte Felsterrasse, auf der $B$. dalmatinus sehr häufig war und $z$. T. in Bohrmuschellöchern saß; gelegentlich wurden dort auch B. sphinx- $\hat{\delta} \delta$ in Löchern gesehen.

Mit diesem Felsen ist die Blennius- und Tripterygion-Fauna von Banyuls-sur-Mer zwar nicht ganz erfaßt, doch konnte auf die Darstellung der Verhältnisse bei B. sanguinolentus (bewohnt dort flachen, sonnigen Geröllstrand) und $B$, pavo (in flachen, geschützten Stellen des Fels) verzichtet werden, da sie keine Abweichungen zu den vorher besprochenen Untersuchungsstellen aufweisen würde. Der spezielle Biotop von $B$. zvonimiri wird im nächsten Kapitel beschrieben. Die Lebensräume von B. rouxi, $T$. xantbosoma und $T$. minor wurden oder werden in anderen Arbeiten behandelt (ZANDER \& HEYMER 1970).

\section{Zur Autökologie und Biologie der Blennius-Arten}

Die Reihenfolge der zu besprechenden Arten wird nach ihrer taxonomischen $\mathrm{Zu}$ ordnung, wie sie NORMAN (1943) vorgeschlagen und von ZANDER (1972b) leicht verändert wurde, vorgenommen. Die im Mittelmeer vertretenen Arten gehören danach folgenden Untergattungen und Artengruppen an:

$\begin{array}{lll}\text { Untergattung Salaria: } & \text { Cristatus-Gruppe: } & \text { B. cristatus } \\ & \text { Gattorugine-Gruppe: } & \text { B. gattorugine, B. tentacularis, } B . \\ & \text { vandervekeni, B. sanguinolentus; } \\ & \text { Fluviatilis-Gruppe: } & \text { B. pavo, B. basiliscus } \\ \text { Sphinx-Gruppe: } & \text { B. sphinx, B, incognitus, B. zvoni- } \\ & \text { miri, B. rouxi }\end{array}$




$\begin{array}{lll}\text { Untergattung Blennius: } & \text { B. ocellaris } \\ \text { Untergattung Lipophrys: Pholis-Gruppe: } & \text { B.trigloides } \\ & \text { Canevae-Gruppe: } & \text { B. canevae, B. nigriceps, B. adria- } \\ & \text { ticus, } B \text {. dalmatinus } \\ \text { Untergattung Coryphoblennius: } & \text { B. galerita }\end{array}$

Außer biologischen Merkmalen werden z. T. auch morphologische Besonderheiten, die im direkten Zusammenhang mit der Okologie der betreffenden Arten stehen, diskutiert (Körpergestalt, Bau der Flossenstrahlen und des Seitenorgansystems). Die Struktur der Flossen wurde allerdings schon früher (ZANDER 1972a) im Zusammenhang mit der vertikalen Verbreitung der verschiedenen Arten behandelt.

\section{Blennius cristatus L.}

Diese Art ist ein typischer Bewohner des Brandungsbereiches. An den Fundstellen der algerischen, marokkanischen und spanischen Küste waren die Tiere an steilen, dem offenen Meer zugewendeten Felsen nahe der Wasseroberfläche oder auf wellenüberspülten Plateaus zu finden. Dabei suchten sie optische Verstecke wie Mulden oder sogar Löcher im Fels, of aber nur dichte Algenbüschel auf. Sie stellen keine Lichtansprüche, denn sie halten sich sowohl an besonnten als auch an schattigen Plätzen auf. Da die Fluchtdistanz sehr kurz ist, waren die Tiere relativ leicht $z u$ fangen.

Das Fehlen von $B$. cristatus an den nordspanischen und französischen Fundstellen 13-20 mag darauf zurüdkzuführen sein, daß es sich bei dieser Art um eine warmstenotherme Form handelt, die im nördlichen Mittelmeer und im Schwarzen Meer fehlt (ZANDER 1972b). Unklar ist dann allerdings das Fehlen dieser Art an den libyschen und tunesischen Fundstellen.

Im Körperbau weist $B$. cristatus einige Besonderheiten auf, die als Anpassungen an die Lebensweise in der Brandungszone aufgefaßt werden können. Der Körper ist von plumper, gedrungener Gestalt, die Kopfunterseite relativ breit; dadurch wird erreicht, daß eine größere Fläche des Körpers dem Substrat aufliegt. Die Flossen sind z. T. zu Klammerorganen entwickelt, da die Analis und die 4 unteren Pectoralia-Strahlen in Häkchen auslaufen; die Ventralia sind relativ kurz und kräftig entwickelt (Abb. 12a, b). Mit diesen Sonderbildungen können diese Fische der Brandung widerstehen, ohne vom Felsen fortgespült zu werden (ZANDER 1972a). An den Flossen- und Körperteilen, die mit dem Substrat in Berïhrung kommen, ist eine Cuticula ausgebildet. B. cristatus besitzt ferner von allen untersuchten Blenniws-Arten das am höchsten entwickelte Kopfkanal-/Seitenliniensystem (Abb. 12a). Der Supraorbitalring weist bis zu 5, der Praeopercularring bis zu 3 Reihen dicht nebeneinanderliegender Porenringe auf. Die Seitenlinie reicht bis auf den Schwanzstiel, am vorderen Körperabschnitt führen von ihr dorsal und ventral Seitenkanälchen und münden jeweils in mehreren Poren nach außen. Dieses Merknal wird als altertümliches Gattungsmerkmal gewertet, das ein Relikt der suprademersen Lebensweise darstellt (ZANDER 1972b). Uber weitere morphologische Merkmale und über die Färbung berichtet BATH (1970). Nachzutragen wäre höchstens, daß bei Exemplaren aus Annaba (6) der Bauch auffallend rötlich gefärbt war. 

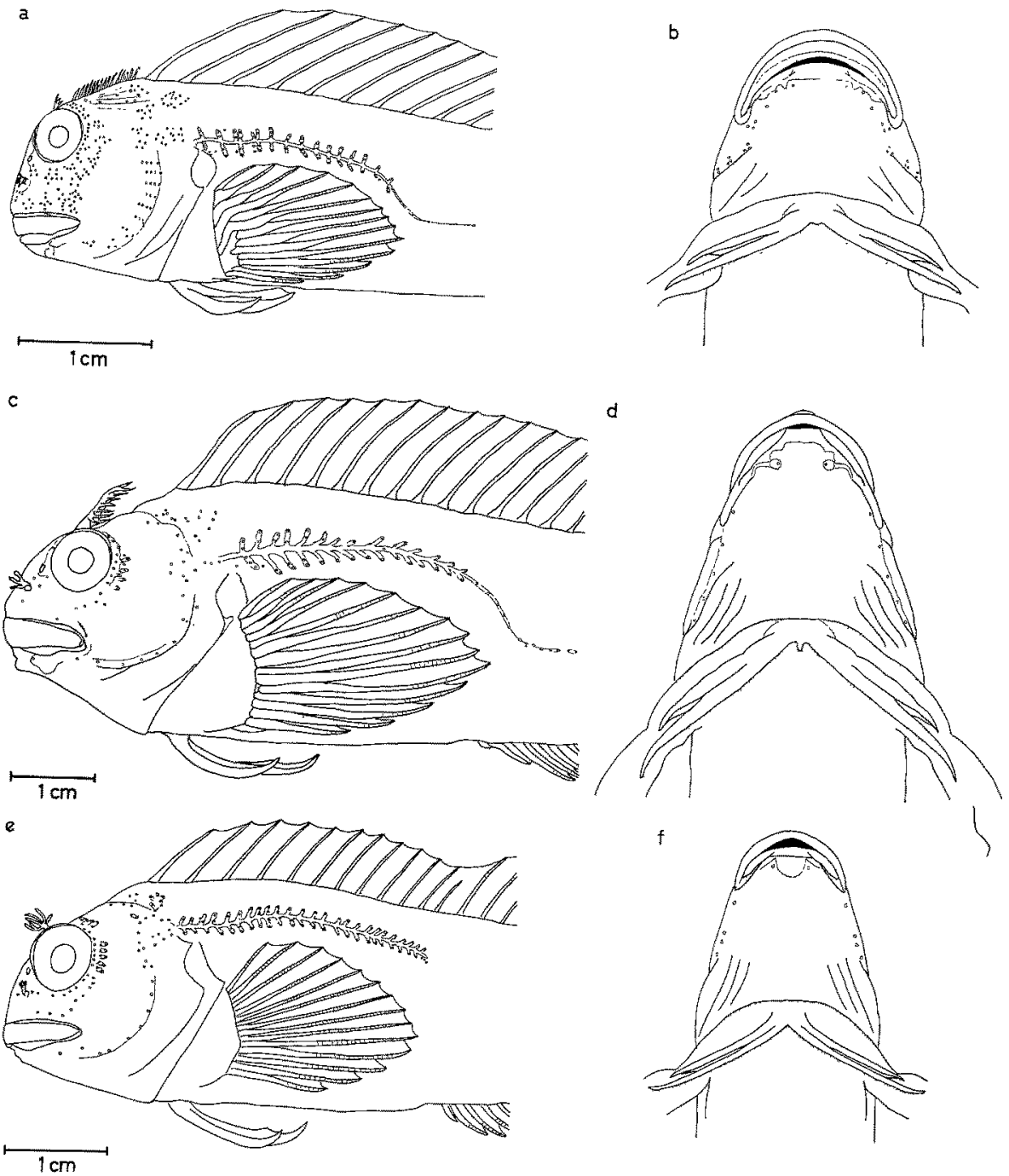

Abb. 12: a Blennius cristatus, Seitenansicht des Vorderkörpers, $b$ Kopfunterseite; c Blennius gattorugine, Seitenansicht des Vorderkörpers, $d$ Kopfunterseite; e Blennius vandervekeni, Seitenansicht des Vorderkörpers, $f$ Kopfunterseite

\section{Blennius gattorugine BRÜNNICH}

Hinsichtlich der Tiefenverbreitung dieser Art konnte die interessante Feststellung gemadh werden, daß die Adulten meistens erst ab $1 \mathrm{~m}$ Wassertiefe zu finden sind, Jungfische aber bis $30 \mathrm{~cm}$ unter dem Wasserspiegel vorkommen (ZANDER 1972a). Die Adulten hielten sich vorwiegend an senkrechten Wänden, häufig an überhängenden Felsen oder zwischen Geröll auf. In Banyuls-sur-Mer sind sie noch in $10 \mathrm{~m}$ Tiefe, oft 
auch in den dichten Posidonia-Beständen festgestellt worden. Der Bewuchs spielt keine Rolle bei der Biotopwahl, dagegen aber das Vorhandensein optischer Höhlen in Form ron Löchern und Spalten im Fels, da diese Art sehr scheu ist und bei Annäherung schnell flieht. Die Angaben Abers (1962) hinsichtlich Frequenz (Verteilung im Biotop), die groß ist, und Abundanz (Häufigkeit an bestimmten Plätzen), die gering ist, können bestätigt werden. Das gilt evtl. nicht für die Jungfische, die zu mehreren im flachen Bereich an wenig abfallenden Felsen beobachtet wurden, vergesellschaftet mit $B$. sphinx, $B$. canevae und $B$. incognitus.

Diese Art ist kompreß und relativ hochrückig gestaltet. Die Ventralia und die Pectoralia, deren 4 untere Strahlen in Häkchen auslaufen, sind mittelkräftig gestaltet, sehr wahrscheinlich eine Anpassung der Jungfische an die Lebensweise im Turbulenzbereich (ZANDER 1972a). An den genannten Flossen ist eine schwache Cuticula ausgebildet. Das Kopfkanal-/Seitenliniensystem (Abb. 12c, d) ist nicht mehr so gut entwickelt wie das von $B$. cristatus. Der Supraorbitalring weist 2-3 Porenreihen auf, der Praeopercularring besitzt nur am Beginn der Seitenlinie sehr viele, sonst nur jeweils 1 Pore. Der Supratemporalkanal ist noch mit vielen Poren ausgestattet. Die Seitenlinie weist im vorderen Abschnitt dorsale und ventrale Seitenkanälchen auf, die jeweils mit mehreren Poren enden. Im caudalen Abschnitt fehlen diese, einige Poren liegen direkt auf dem Hauptkanal. Im Maul sind die Eckzähne in beiden Kiefern sehr schwach ausgebildet, offenbar ein ursprüngliches Merkmal.

\section{Blennius vandervekeni POLI}

Diese Art wurde bereits früher kurz ökologisch beschrieben (ZANDER 1969). Sie wurde im Mittelmeer nur in Algerien und Marokko und von BATH (1966) auch in Südspanien gefunden. Offenbar handelt es sich bei dieser Art um einen späten Einwanderer ins Mittelmeer (Erstbeschreibung aus Angola; Poll 1959). An den Untersuchungsstellen wurde diese Art an schrägen oder senkrechten Felsen ab $30 \mathrm{~cm}$ unter der MWL gefunden, ohne daß Ansprüche an Licht oder Bewuchs gestellt werden. Die Fluchtdistanz ist groß, als Verstecke werden sowohl dichte Algenbestände als auch Spalten und Löcher des nicht bewachsenen Substrats aufgesucht (optische Höhlen). Die Abundanz dieser Art war an den Fundstellen mit tief abfallenden Felsen $(8=$ Berard, $9=$ Kristel $)$ am größten.

Uber die Morphologie, die Färbung und den Farbwechsel liegt die Beschreibung BATHs (1966) vor. Die Stärke der Flossenstrahlen erreicht nicht die von B. cristatus oder auch $B$. gattorugine. Die 4 ventralen Strahlen der Pectoralia laufen zwar auch in Häkchen aus, diese sind aber relativ schwach gebaut (Abb. 12e,f). Die gleiche Feststellung gilt für die Analis-Strahlen sowie für die langen schlanken Ventralia. Eine Cuticula ist ganz schwach nur an den Ventralia und unteren Pectoralia-Strahlen zu erkennen. Das Kopfkanalsystem ähnelt dem von $B$. gattorugine, die Seitenlinie von $B$. vandervekeni endet allerdings schon in Höhe der Spitze der Pectoralia (Abb.12e). Der Körperhabitus gleicht dem von $B$. gattorugine, ohne aber eventuell so hochrïckig gestaltet $z u$ sein wie jene Art. Eckzähne sind hier in beiden Kiefern vorhanden. 


\section{Blennius sanguinolentus PaLlas}

Den typischen Lebensraum dieser Art bilden horizontale Ebenen, die mit Geröll und Gesteinstrümmern belegt sind; ein Nebenhabitat, das sehr of an der nordafrikanischen Küste gefunden wurde, war die Grenze von Felsabfall zum Sandgrund. Die bevorzugte Tiefe liegt bei $50 \mathrm{~cm}$, in Dramont (19) war nach von HACHT in 1,5 m eine dichte Besiedlung zu vermerken. Das meist dem direkten Sonnenlicht ausgesetzte Habitat ist bis auf feine Grünalgen stets aufwuchslos. An solchen Stellen zeigt diese Art eine hohe Abundanz. Die größte Aktivität zeigen die Tiere bei Sonnenschein, bei dem sie aber auf den Steinen sitzen und beobachten, während sie bei bedecktem Himmel oder in der Dämmerung zwischen dem Geröll sitzen und nur mit dem Kopf hervorschauen (VON HACHT). Thre Fluchtdistanz ist äußerst groß, sie sind daher nur schwer mit einem Handnetz zu fangen. Andererseits ist ihr Erkundungsverhalten sehr ausgeprägt, da die Tiere, die nach Störung in ihre Verstecke unter Geröll flüchten, sehr schnell wieder herrorschwimmen. Bevor sie in ihre Höhlen schwimmen, färben sich die hell marmorierten Fische dunkel um. Auf Grund seiner sehr weiten geographischen Verbreitung kann diese Art als eurytherm angesehen werden (ZANDER 1972b).

Im Biotop kann $B$. sanguinolentus bei oberflächlicher Betrachtung mit $B$. vandervekeni verwechselt werden, besonders wenn letzterer die "Fleckenzeichnung " (BATH 1966) zeigt. $B$. sanguinolentus besitzt jedoch kleinere Orbitaltentakel und eine höhere 1. Dorsalis (Abb. 12e und 13a, b). Bei dieser Art ist das Kopfkanalsystem reduziert, da der Augenring nur noch eine Porenreihe aufweist und in der Präopercularreihe nur noch wenige Poren zu finden sind. Die Seitenlinie, die noch um die Pectoralia herumführt, endet in Höhe des Analisbeginns (Abb. 13a); es werden keine deutlichen Nebenkanälchen mehr ausgebildet, Poren befinden sich dort nur noch auf und dorsal vom Hauptkanal. Die Flossenstrahlen der Pectoralia, Ventralia und Analis sind noch schwächer als bei $B$. vandervekeni ausgebildet (ZANDER 1972a), eine Cuticula ist nur an den Ventralia vorhanden.

\section{Blennius pavo Risso}

Die Habitatwahl dieser Art ähnelt weitgehend der von $B$. sanguinolentus, da ebenfalls flache, horizontal gelegene Stellen mit Geröllbelag bevorzugt werden. So wurden z. B. beide Arten zusammen in den Fundstellen 4 (Kelibia) und 12 (Calpe) beobachtet. Im allgemeinen wird $B$. pavo aber an noch flacheren. Stellen, ab $10 \mathrm{~cm}$ unter der Wasseroberfläche gefunden. Diese Art ist extrem euryhalin, darauf kann sehr wahrscheinlich zurückgeführt werden, daß diese Art im Fundort 3 (Djerba) als einzige, und zwwar in großer Frequenz und Abundanz vorkam; vermutlich gab es dort Süßwassereinflüsse, die die Posidonia-Bestände zum Verfaulen brachten und daher das Wasser stark trübten. Ahnliche Verhältnisse wurden auch im Etang des Salses in Suidfrankreich, wo ein Salzgehalt von 22\% gemessen wurde, gefunden. An den anderen beschriebenen Stellen war die Abundanz unter der Konkurrenz der übrigen Arten sehr viel geringer. Diese Fische verbergen sich in optischen Höhlen zwischen Geröll oder in Spalten, in Banyuls (=13) auch in Bohrmuschellöchern, die $10 \mathrm{~cm}$ unter der NWL im horizontalen Fels lagen. Die Fluchtdistanz ist sehr viel geringer als bei $B$. sanguinolentus. 
a

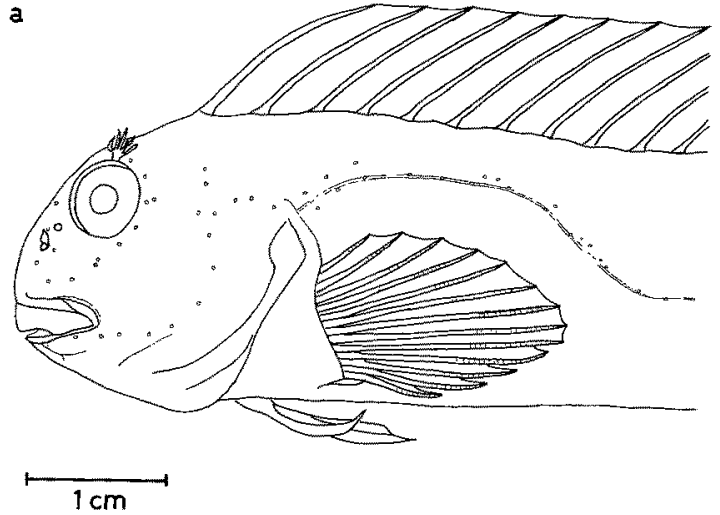

c

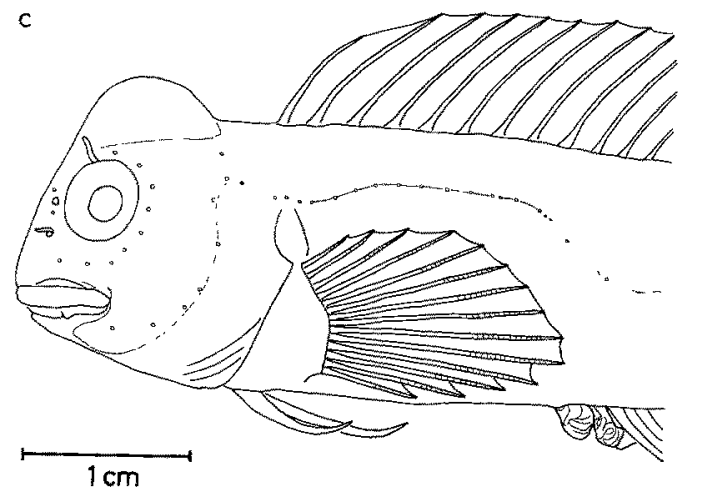

b
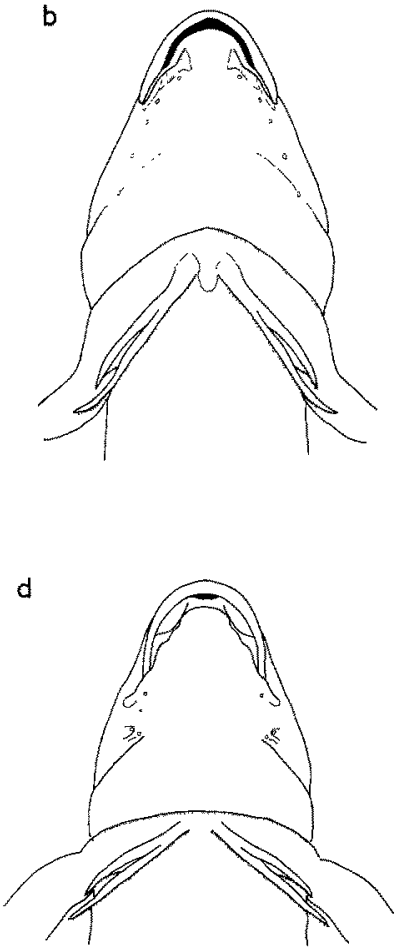

Abb. 13: a Blennius sangtinolentus, Seitenansicht des Vorderkörpers, $b$ Kopfunterseite; $c$ Blennius pawo, Seitenansicht des Vorderkörpers, $d$ Kopfunterseite

Die $\delta$ von $B$. pavo zeichnen sich durch einen Nackenkamm aus, der unter den anderen Blennius-Arten im Mittelmeer nur noch von B. basiliscus und andeutungsweise von $B$. adriaticus (BATH 1971) entwickelt wird. Die Tiere sind weniger hochrückig und schlanker als die bisher beschriebenen Arten, der Körper erscheint stark kompreß. Das Kopfkanalsystem gleicht dem von B. sanguinolentus (Abb. 13c), die Seitenlinie ist aber noch weiter reduziert, da Poren nur noch auf dem Hauptkanal zu finden sind, die letzte in Höhe des Analisanfanges. Die Flossenstrahlen der Pectoralia und Analis sind nicht besonders kräftig, ihre Enden nur wenig hakenförmig gebogen. Die Ventralia laufen in lange, schlanke Flossenarme aus, mit denen sich die Fische zwar abstützen, aber kaum festklammern können (Abb. 13d). Eine Cuticula ist nicht wahrnehmbar.

\section{Blennius sphinx Cuvier \& VALENCIENNES}

Diese Art ist einer der häufigsten Fische des oberen Felslitorals im Mittelmeerraum. Thren bevorzugten Lebensraum bilden die besonnten, algenbestandenen horizon- 
talen oder schwach geneigten Felsen an oder nahe der Wasseroberfläche. B. spbinx kommt an geschützten Biotopen genauso vor wie an solchen, die der Brandung ausgesetzt sind; dort vermag sich diese Art an den Unebenheiten des Substrats anzuklammern, wenn die Wellen auf- oder ablaufen und dann das Habitat kurzzeitig trockenfält. Außerhalb der Laichzeit suchen die Tiere auch bei Störung keine Höhlen auf. Der Fluchtweg führt stets nach oben und verläuft daher oft außerhalb des Wassers, die Fluchtdistanz ist allerdings äußerst gering. Meist schwimmen die Fische auf den Felsen umher und suchen zwischen den Algen nach Futter. Tiefer als $40 \mathrm{~cm}$ unter der NWL sind sie dann kaum anzutreffen. Während der Laichzeit streifen nur die $q 9$ auf den Felsen umher, die ô $\delta$ sitzen dann in ihrem Körperdurchmesser entsprechenden Bohrmuschellöchern (nach Beobachtungen in Banyuls und Tarragona). Diese haptischen Höhlen werden häufig noch in 1,5 m, manchmal sogar in $2 \mathrm{~m}$ Tiefe in Besitz genommen und gegen andere $\hat{\delta} \hat{o}$ verteidigt. Bereits auf GuITEL (1893) gehen die Beobachtungen zurück, daß die Gelege eines of von verschiedenen $q$ 우 stammen; diese Feststellung gilt sehr wahrscheinlich allgemein für die Gattung Blennius. B. spbinx- $\delta \hat{\delta}$, die in ihrem Loch Laich bewachen, schauen meist mit ihrem vorderen Körperdrittel aus der Höhle heraus und beobachten die Umwelt sehr genau. Dabei stïtzen sie sich nach einer Seite gerichtet auf die Ventralia ab, während die dem Beobachtungsobjekt zugewendete Brustflosse stark fächelt. Auch die „Bauch-oben“-Stellung konnte dabei festgestellt werden. Nach Ausflügen auf den freien Felsen fädeln sich die $\delta \hat{\delta}$ meist rüickwärts wieder ein, wie es ABEL (1962) bei $B$. canevae beschrieben hat. Kommt ein $O$ in Sichtweite eines $\hat{O}$, so nimmt die Frequenz der Bewegungen der Brustflosse $z u$, gleichzeitig wird die hohe 1. Dorsalis abwechselnd mehrfach aufgerichtet und wieder abgesenkt (vgl. auch GuITel 1893), während sich das ot etwa zur Hälfte aus dem Loch schiebt. Wenn das + näher kommt, wird der Kopf mehrmals hochgebäumt (Kopfwackeln), wobei die vordere Dorsalis aufgerichtet bleibt. Wenn ein laichwilliges $O$, auf diese Weise angelockt, zum Loch schwimmt, kommt das ô ganz heraus und wiederholt das Kopfwackeln. Schließlich schlïpt das 9 in die Höhle und laicht meistens bauchoben an die Decke ab. Das ô wartet während der Eiablage vor der Höhle; falls diese aber geräumig genug ist, schwimmt es selbst mit hinein und wartet dort das Ende des Laichvorganges $a b$, ehe es das $O$ vertreibt. Gelegentlich kam es sogar vor, daß bis zu 3 우우 gleichzeitig in der Höhle waren, nachdem sie nacheinander vom angelockt waren. Die oben geschilderten, auf Grund von Bewegungen mit hohen Frequenzen hervorgerufenen optischen Signale (Dorsalisaufrichten, Kopfwackeln) werden durch weitere Merkmale verstärkt. So ist die 1. Dorsalis des ô sehr viel höher als der hintere Abschnitt (bei 우 etwa gleich hoch) und auffällig rötlich-orange gefärbt. Die leuchtendorangen Augententakel sind ebenfalls größer als bei den $Q$ 우, bei älteren $\delta \hat{\delta}$ sogar an der Spitze aufgespalten. Am Kopf fällt der intensiv blaue Fleck hinter dem Auge, der rot und schwarz eingefaßt ist, sehr auf. Pectoralia und Ventralia leuchten ebenfalls orange.

Uber das Rivalenverhalten der $\delta$ liegen weit weniger Beobachtungen vor, die sich nicht in ein einheitliches Schema bringen ließen. Wenn ein umherstreifendes ô ein lochbewohnendes bedroht, so bleibt es in geringem Abstand - ca. $10 \mathrm{~cm}$ - vor diesem sitzen und zeigt schnelles Kopfwackeln, wobei die Dorsalis nur nach Beendigung dieser Bewegung kurz aufgerichtet wird. Der Angegriffene versucht den Rivalen durch Beiß- 
a
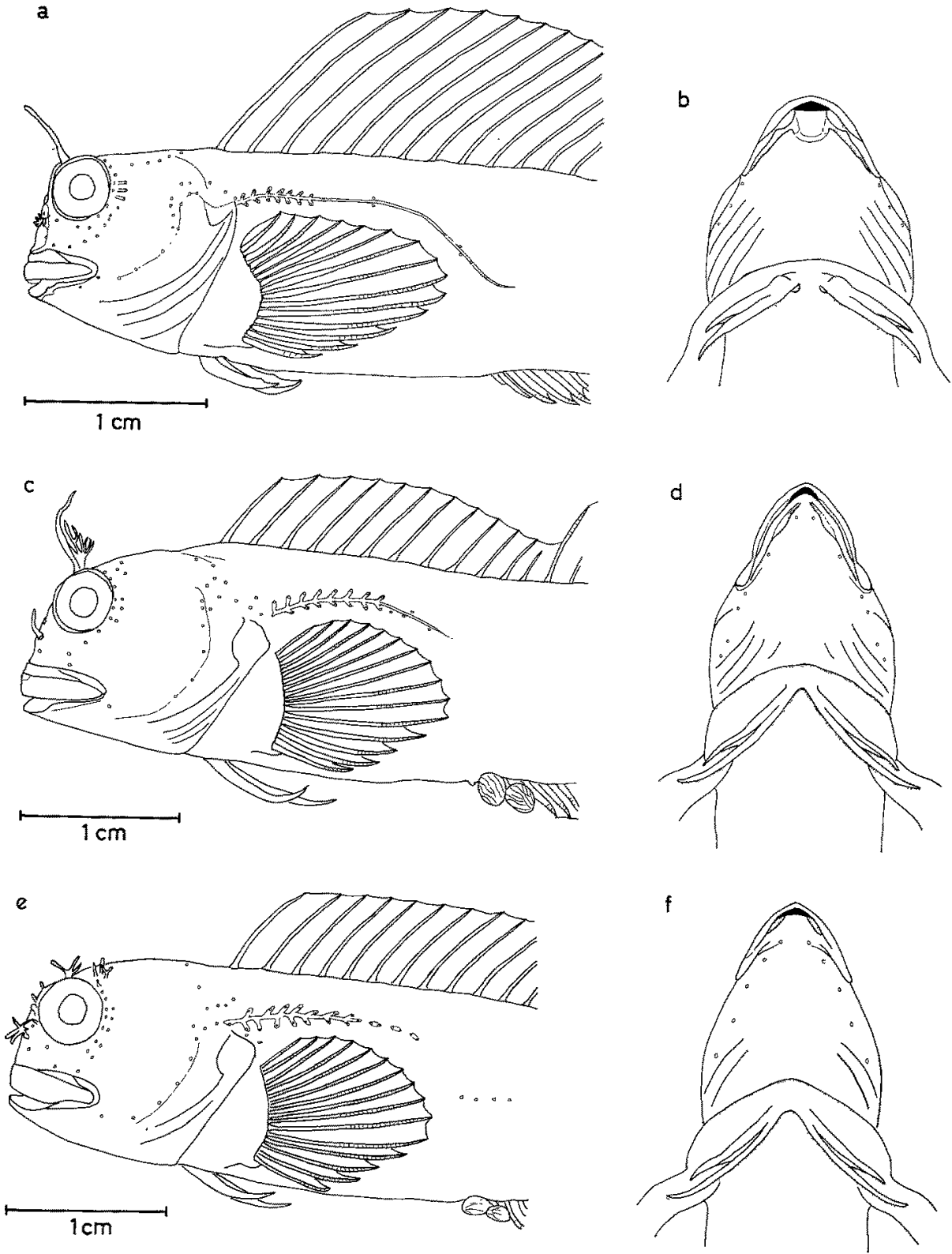

Abb. 14: a Blennius sphinx, Seitenansicht des Vorderkörpers, $b$ Kopfunterseite; $c$ Blennius incognitus, Seitenansicht des Vorderkörpers, $d$ Kopfunterseite; $e$ Blennius zvonimiri, Seitenansicht des Vorderkörpers, $f$ Kopfunterseite

angriffe zu vertreiben, wobei er möglichst im Kontakt mit dem Loch zu bleiben versucht; wenn er sich aus der Höhle begibt, wird er auch vom Angreifer durch Beißen attackiert. In einem anderen Fall, in dem das umherstreifende $\delta$ weitaus größer als 
das lochbewohnende war, schwamm letzteres blitzschnell aus der Höhle heraus und umkreiste den Eindringling mit ruckartigen Bewegungen, der aber von dem kleineren kieine Notiz nahm und schließlich fortschwamm. Daraufhin fädelte sich der Höhlenbesitzer wieder ein. Bei 2 umherstreifenden, gleich großen o o $\delta$ wurde nur ein Umkreisen mit aufgerichteten Dorsalflossen beobachtet, das so lange andauerte, bis eines fortschwamm. Die Brutzeit begann in Tarragona Ende April; in Banyuls dauerte sie bis Ende Juli an.

Da diese Art außerhalb der Laichzeit knapp unterhalb der Wasseroberfläche lebt und oft der Brandung ausgesetzt ist, weist sie im Körperbau einige Anpassungen an diese Lebensweise auf. Die als Klammerorgane fungierenden Pectoralia-, Ventraliaund Analisstrahlen sind kurz, aber kräftig gestaltet (Abb. 14a, b) (ZANDER 1972a). An den Flossenteilen, die mit dem Substrat in Berïhrung kommen, ist eine dicke Cuticula vorhanden. Der Vorderkörper ist von plumper Gestalt mit breiter ventraler Aufsetzfläche, die in dem speziellen Biotop der Gefahr des Abrutschens entgegenwirken kann. Das Kopfkanalsystem besteht aus einem doppelten Augenring und einem einfachen Präopercularring (Abb. 14a). Die Seitenlinie führt noch ganz um die Pectoralia herum, besitzt aber nur in ihrem vorderen Abschnitt Nebenkanälchen.

\section{Blennius incognitus BATH}

Diese Art ist in bestimmten Biotopen genauso häufig wie $B$. sphinx $(12=$ Calpe $)$, in anderen kann sie dagegen sehr selten sein oder vollkommen fehlen $(9=$ Kristel, $10=$ Al Hoceima). B. incognitus ist besonders aus den Arbeiten Abels $(1962,1964)$ als $B$. inaequalis bekannt und wurde oft mit dem sehr ähnlichen $B$. zvonimiri verwechselt, ehe BATH (1968) die grundlegenden morphologischen Unterschiede dieser Zwillingsarten herausstellte. Aber auch in ökologischer Hinsicht konnten sie bereits von ABEI (1962) getrennt werden. Während $B$. zvonimiri als eindeutig schattenliebend zu bezeichnen ist, stellt $B$. incognitus keine besonderen Lichtansprüche und ist daher sowohl an schattigen als auch besonnten Biotopen zu finden. Bevorzugt werden stark geneigte oder senkrechte Wände vor horizontal liegenden oder wenig abfallenden Plateaus. Die größte Abundanz scheint zwischen 60 und $100 \mathrm{~cm}$ unterhalb der Wasseroberfläche zu liegen und nimmt in der Regel bis in eine Tiefe von $30 \mathrm{~cm}$ hinauf stetig ab. An Fundstellen mit sehr starker Brandung $(8=$ Berard) wurde $B$. incognitus nicht oberhalb von $50 \mathrm{~cm}$ beobachtet; dort besiedelte er auffallend oft horizontal liegende Substrate. Die eigentliche Brandungszone wird gemieden. Unterhalb $1 \mathrm{~m}$ Wassertiefe nimmt die Besiedlungsdichte wieder merklich $a b$, hier sind besonders „brütende" $\approx \hat{\sigma}$ und die durch diese angelockten laichwilligen 9 우 zu beobachten. Die Brutpflege treibenden $\delta \delta$ sitzen in haptischen Höhlen, während die umherstreifenden Tiere als Versteck auch dichte Algenbüschel, also optische Versteckplätze aufsuchen. Aus diesem Grund wird sehr wahrscheinlich Felsen mit lockerem Algenbewuchs als Habitat bevorzugt. Einmal wurde auch beobachtet, daß eine Anemona sulcata aufgesucht wurde, ohne daß der Fisch genesselt wurde.

Das Balz- und Aggressionsverhalten ist von ABEL (1964) genau beschrieben worden. Allerdings muß diesem Autor widersprochen werden, wenn er meint, daß die $\hat{o} \hat{\alpha}$ 
keine vom $Q$ abweichende Färbung besitzen. BATH (1968) konnte eine große Variabilität der Färbung der $\delta \hat{\delta}$ zur Laichzeit feststellen, die deutlich von der der 웅 verschieden ist. Von mir wurden $\hat{\delta} \hat{\delta}$ gesehen, die eine gelbe, rote, purpurne, braune, grüne oder olivene Grundfärbung zeigten, wobei beobachtet wurde, daß Schokoladenbraun in Rot, Dunkelbraun in Gelb übergehen konnte; ein Wechsel zwischen Rot und Gelb wurde nicht bemerkt.

Uber die Dauer der Laichzeit kann noch nichts Genaues gesagt werden. In Tarragona streiften die $\hat{\delta} \delta^{\circ}$ am 15. 5. 1971 (Wassertemperatur $16-17^{\circ} \mathrm{C}$ ) noch auf den Felsen umher, obwohl sie bereits durch verlängerte Augententakel und kräftigere Färbung von den 웅 unterschieden waren. In Banyuls waren sie am 20.7.1970 vollauf bei der Brutpflege, und auch voN HACHT beobachtete noch am 9.8.1970 in Dramont (=19) $\hat{\partial} \hat{o}$ in Löchern. An der libyschen Küste wurden am 12.8.1968 noch $\hat{o} \hat{o}$ in Fortpflanzungsbereitschaft beobachtet, die durch extrem lange Orbitaltentakel auffielen. Im Aquarium schließlich bewachte ein aus Tarragona stammendes $\hat{\delta}$ am 5. August ein Gelege, das von $2 q 0$ herstammte. Die Laichzeit von $B$. incognitus beginnt und endet also später als die von $B$. spbinx. Offensichtlich sind für $B$, incognitus die Entwicklungsbedingungen bei höheren Temperaturen günstiger, obwohl diese Art das gleiche Verbreitungsgebiet mit $B$. sphinx teilt und daher als eurytherm angesprochen werden muß.

Die $\delta \delta$ sind zur Laichzeit sehr aggressiv und drohen mit aufgespertem Maul. Einzelheiten über das Verhalten sind bei ABEL. (1964) zu finden.

Die Körpergestalt dieser nicht in der Brandungszone lebenden Art ist mehr kompreß und schlanker als bei $B . \operatorname{sphinx}$. Die Häkchen an den Flossenstrahlen sind hier schwächer (Abb.14c, d), eine Cuticula kaum wahrnehmbar nur an den Spitzen der Ventralia ausgebildet. In dem Kopfkanal- und Seitenliniensystem ähnelt sie weitgehend $B$. spbinx, die Seitenlinie führt allerdings nicht mehr ganz um die Pectoralia herum (Abb. 14c). Außer durch eine abweichende Färbung sind die $\delta \hat{\delta}$ durch einen langen Orbitaltentakel zur Fortplanzungszeit kenntlich, der aus einem Hauptast besteht und an der Basis aufgefiedert ist; bei den 00 und außerhalb der Laichzeit auch bei den $\delta \hat{\delta}$ bleibt der Hauptast wesentlich kürzer.

\section{Blennius zvonimiri Kolombatovic}

Diese Art, die morphologisch B. incognitus sehr ähnlich ist, unterscheidet sich von jener deutlich in ihrer Okologie. Wie nach Beobachtungen in Banyuls (13 und 18) festgestellt wurde, kommt diese Art in extrem schattigen Biotopen, z. T. gemeinsam mit Tripterygion minor vor. Erst bei Tauchgängen mit Taschenlampen konnten sie in Höhlen an der Hafenmole von Banyuls in den Spalten des Mauerwerks entdeckt werden. Auch unter extrem überhängenden Felsen waren sie in ca. $2,5 \mathrm{~m}$ Tiefe recht zahlreich, wo sie sich häufig in Bohrmuschellöchern aufhielten. Zu bestimmten Tageszeiten, wenn der gesamte Biotop im Schatten liegt, kamen diese Fische auf die oberen, dem Tageslicht ausgesetzten Felsen bis auf $1 \mathrm{~m}$ unter die NWL heraufgeschwommen und suchten zwischen den Algen sehr intensiv nach Futter. Wurden die Tiere dort gestört, so ging ihr Fluchtweg zunächst nach unten bis zur Kante des vertikalen Felsabfalles, wo sie zu- 
nächst verharrten und erst nach weiterer Verfolgung in die Löcher unter den überhängenden Felsen flohen (Abb. 15).

Auffällig bei dieser Form ist die von allen bisher beobachteten Blennius-Arten abweichende Schwimmweise. Wie ABEL (1962) beschrieb, ist für Blennius ein Schlängelschwimmen des ganzen Körpers („anguilliform"), bei der die Pectoralia nur beim Start kräftig schlagen, typisch. Diese Bewegungsform ist auch bei $B$. zvonimiri gelegentlich zu beobachten. Meistens wird jedoch eine ruckweise Schwimmweise angewendet, bei der

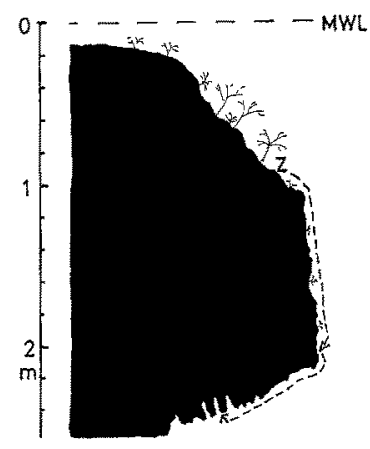

Abb. 15: Spezieller Okotop von Blennius zvonimiri ( $Z$ ), nach Beobachtungen in Fundstelle 13 (Banyuls-sur-Mer). Der Fluchtweg ist durch eine gestrichelte Linie gekennzeichnet. MWL: Mittelwasserlinie

der Schwanz zwar audh schlängelt, die Brustflossen aber bei jeder ihrer Phasen synchron schlagen ("caringiform"). Ahnlich schwimmt z. B. Gobius (vgl. ABEL 1962), bei dem aber die Amplitude des Schwanzschlages geringer zu sein scheint.

Auffallend bei $B$. zvonimiri ist ferner die Zeichnung. Auf der schokoladenbraunen Grundfärbung treten an der Dorsalseite 7 leuchtend gelb-weiße Flecken, an der Schwanzwurzel eine schwarze Markierung hervor. Weitere Einzelheiten über die Färbung findet man bei BATH (1968). Damit gibt es bestimmte Übereinstimmungen mit der Zeichnung anderer schatten- oder höhlenbewohnender Formen, z. B. Tripterygion xanthosoma (Schwanzstielfleck) und T. minor (helle Rückenflecken).

In morphologischer Hinsicht gleicht $B$, zvonimiri weitgehend $B$. incognitus (BATH 1968). Diese Feststellung gilt sowohl für die Ausbildung der Flossenstrahlen als auch für das Kopfkanal-iSeitenliniensystem (Abb. 14e, f). Unterschiede gibt es höchstens in der Tentakelzahl und -anordnung, da diese bei $B$. zvonimiri erheblich vermehrt und überall auf dem Kopf zu finden sind.

\section{Blennius trigloides Cuvier \& Valenciennes}

Diese Art ist wie $B$. cristatus ein typischer Bewohner des Brandungsbereiches. Sie führt dort eine verborgene Lebensweise, da sie sich bevorzugt in Mulden, Spalten und unter überhängenden Felsen aufhält, die unmittelbar an der Wasseroberfläche liegen. Obwohl sich diese Fische meistens in schattigen Habitaten ohne Aufwuchs befanden, 
muß diese Art - wie ABeL (1962) schon feststellte - als euryphot bezeichnet werden. In Biotopen, die sehr starker Brandung ausgesetzt waren $(9=$ Kristel, $20=$ Tarragona), waren sie nämlich vorzugsweise an besonnten Plätzen zu finden. Diese Art fehlte an solchen Fundorten, die eventuell im Sommer zu hohe Temperaturen aufweisen (libysche und tunesische Küste) und keine besonders reiche Strukturierung aufweisen ( $5=\mathrm{Ta}$ barka, $10=$ Al Hoceima). In ihren typischen Habitaten, die höchstens bis $1 \mathrm{~m}$ unter die Wasserlinie reichen, war ihre Abundanz stets groß. Ihre Fluchtdistanz ist relativ weit, erreicht jedoch nicht ganz die von $B$. sanguinolentus. Beobachtungen, die außerhalb der Laichzeit durchgeführt wurden, ergaben eine sehr geringe Aktivität der Tiere. Sie sitzen in ihren Verstecken meist unbeweglich und lassen sich von den Brandungswellen nicht stören, auch wenn sie beim Ablaufen des Wassers auf dem Trockenen liegen. In Banyuls wurden im Juli 1969 vier Mulden oder aus Miesmuscheln gebildete Habhöhlen mehrmals täglich kontrolliert und eine stete Besetzung mit $B$. trigloides sehr wahrscheinlich durch jeweils die gleichen Tiere - festgestellt. Während der Beobachtungszeit verharrten die Fische unbeweglich, an ihren Augenbewegungen war allerdings zu erikennen, daß sie die Umgebung musterten.

Die Flossen können sehr vielseitig verwendet werden. Einerseits fungieren sie als Klammerorgane, wenn Brandung herrscht. Die Pectoralia werden dann durch Drehung flach auf das Substrat gepreßt und geben somit den unteren 5, in Häkchen auslaufenden Strahlen bessere Anklammerungsmöglichkeiten; außerdem wird die Analis, deren Strahlen ebenfails in Fäkchen auslaufen, zur Verankerung im Substrat gespreizt. Andererseits wird auch beobachtet, daß diese Art rückwärts "gehen" kann, indem die beiden Brustflossen alternierend von hinten nach vorne auf dem Substrat bewegt werden.

Die Beobadtungen, die Anfang Mai in Tarragona - also am Ende der Laichperiode dieser Art - genacht wurden, zeigten allerdings eine sehr viel größere Aktivität auf. An diesem Fundort wurden besonders $Q$ 오, aber auch einige $\hat{\partial} \hat{\partial}$, am Felsen herumstreifend, gesehen. Ferner wurde festgestellt, daß Pärchen dieser Art in einer Mulde zusammenliegen, aus der sie nur mit dem Kopf hervorschauen.

$B$. trigloides ist eine der Blennius-Arten, die ihre Färbung dem Untergrund anpassen können (auch $B$. canevae und B. galerita). Während normalerweise die Grundfärbung mitteloliv ist und nur eine dunklere Bänderung gezeigt wird, ist bei Aufenthalten auf weißem aufwuchslosem Felsen eine Aufhellung, zwischen Rotalgen ein Umschlagen in ein tiefes Rostrot möglich, wobei nur die Bauchseite silbrig bleibt. Die Färbung der $\hat{\delta} \hat{\delta}$ zur Fortpflanzungszeit kann nach Exemplaren, die in Tarragona gefangen wurden, beschrieben werden. Zu dieser Zeit weist der dunkel-braunolive Körper ïberall grünlich irisierende kleinere Flecken auf. Die Querbänderung ist nur andeutungsweise durch dunkleres Pigment erkennbar. Die 1. Dorsalis ist vorne rötlich, im hinteren Teil gelb wie auch die 2. Dorsalis gezeichnet; beide sind mit einem breiten schwarzen Saum versehen. Die gelbliche, am Ansatz der Flosse rote Caudalis weist einen breiten bräunlichen Rand auf, während die körperfarbene Analis schwarz und ganz außen rot gesäumt ist. Die Ventralia sind grünlich-oliv, die Pectoralia nur am Rand körperfarben, sonst transparent.

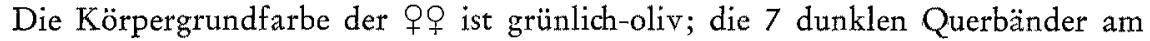
Körper heben sich deutlich ab, ebenso 3 schmalere Binden an der Kopfunterseite. Die gelbe, schwarzgerandete Dorsalis zeigt einige bräunliche Tupfen, ebenso die Caudalis. 

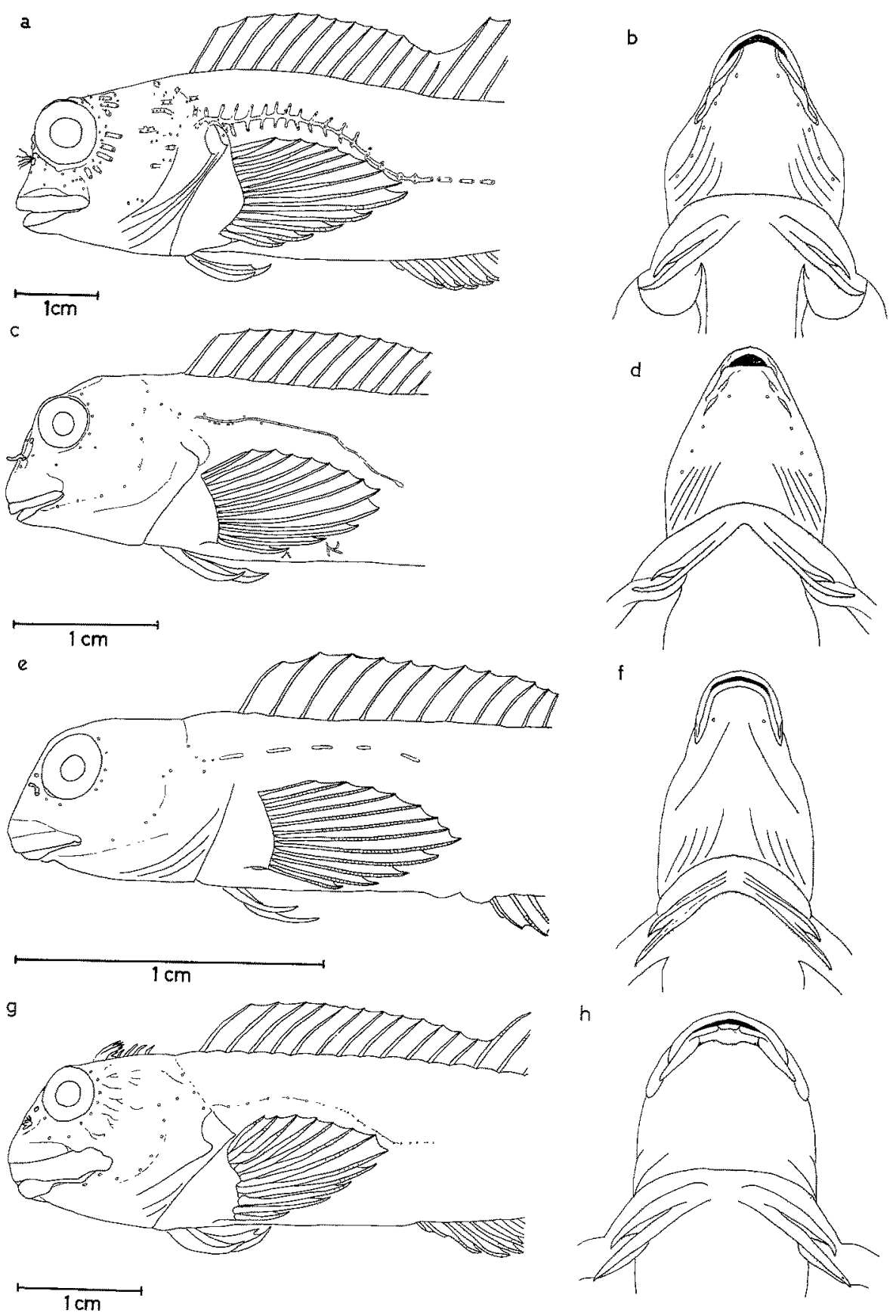

Abb. 16: a Blennius trigloides, Seitenansicht des Vorderkörpers, $b$ Kopfunterseite; $c$ Blennius canevae, Seitenansicht des Vorderkörpers, $d$ Kopfunterseite; e Blennius dalmatinus, Seitenansicht des Vorderkörpers, $f$ Kopfunterseite; $g$ Blennius galerita, Seitenansicht des Vorderkörpers, zu beachten sind die Hautblutgefäße am Kopf, $b$ Kopfunterseite 
Die Analis ist orange und bräunlich gesäumt, sonst gelblich; Ventralia und Pectoralia erscheinen rötlich bis hell bräunlich.

$\mathrm{Da}$ die Flossenstrahlen als kräftige Klammerorgane ausgebildet sind (Abb. 16a, b), ist B. trigloides dem Leben in der Brandungszone gut angepaßt (ZANDER 1972a). Der Körper ist relativ depreß gestaltet, die breite Bauchseite vermag sich dem Untergrund gut anzuschmiegen. An den unteren Strahlen der Pectoralia, an den Ventralia sowie an der ganzen Analis ist eine dicke Cuticula ausgebildet. Das Kopfkanal- und Seitenliniensystem ist sehr gut entwickelt. Der Augenring ist in mehreren Reihen mit deutlich sichtbaren Kanälen manifestiert, ebenso der Präopercularring (Abb. 16a). Die Seitenlinie läuft weit auf den Schwanzstiel hinauf und zeigt im vorderen Teil Nebenkanälchen mit $z$. T. mehreren ausführenden Poren jeweils (Abb. 16a). Aus diesem Grund wird B. trigloides als eine Art angesehen, die primär die Brandungszone besiedelt hat, indem sie von einem Vorfahren (evtl. B. cristatus, vgl. ZANDER 1972b) mit diesem ursprünglichen Merkmal abstammte.

\section{Blennius canevae VINCIGUERRA}

An bestimmten Fundstellen, die durch starke Wasserbewegung und im allgemeinen steil abfallende Felsen gekennzeichnet sind $(8=$ Berard, $9=$ Kristel, $11=$ Mdiq, 13-18 = Banyuls, 20 = Tarragona) gehört $B$. canevae zu den Arten mit hoher Abundanz. Ihre vertikale Verbreitung beginnt etwa $10 \mathrm{~cm}$ unter der Wasseroberfläche und reicht bis in $60 \mathrm{~cm}$, selten bis in $1 \mathrm{~m}$ Tiefe und weiter; sie sind also charakteristische Bewohner der Brandungszone (ZANDER 1972a). Zur OKologie und Ethologie dieser Art hat Abel $(1962,1964)$ ausführliche Darstellungen gebracht. Demnach ist $B$. canevae euryphot, die $\hat{\partial} \hat{o}$ bewohnen haptische Höhlen. Letztere Feststellung gilt allerdings nicht immer nach Beendigung der Fortpflanzungszeit, wenn $\hat{\delta} \hat{\delta}$ wie $\phi Q$ herumstreifend angetroffen werden. Als Versteckplätze werden dann auch optische Höhlen wie dichte Algenbüschel oder auch die Stacheln von Seeigeln aufgesucht. Die Fluchtdistanz ist etwas größer als die von $B$. sphinx, die Fluchtrichtung führt meistens in Richtung Wasseroberfläche.

Nach Beobachtungen in Tarragona trieben die $\delta \hat{\delta}$ bereits Ende April Brutpflege (Wasertemperatur $16-17^{\circ} \mathrm{C}$ ). Das Ende der Laichperiode lag in Banyuls etwa Mitte $J u l i$, da die $\delta \hat{\delta}$ z zunehmend herumstreiften und ihre Balzfärbung verloren. Allerdings fiel von Hactr noch am 15.8.1970 in Dramont $(=19)$ ein gelbkehliges $\hat{O}$ in einem Bohrmuschelloch auf. Nach Beendigung der Laichzeit werden anscheinend Wanderungen unternommen, und die Tiere besiedeln dann Felsen, die vorher von ihnen unbewohnt waren (VoN HACHT). Demgegenüber beobachtete ABEL, daß $B$. canevae im Gegensatz zu $B$. incognitus in Banyuls standorttreu blieb.

Ahnlich $B$. trigloides ist $B$. canevae zu einem intensiven Farbwechsel fähig, der sogar noch über denjenigen der eben genannten Art hinausgeht. So erfolgt er bei $B$. canevae nicht nur bei Oberwechseln auf andersfarbigen Untergrund oder zur Laichzeit, sondern bringt auch Stimmungen der Tiere zum Ausdruck (Abb. 17). (1) Besitztracht: Solche Tiere, die Besitz von einer Höhle genommen haben, zeigen eine dunkle, braunschwarze Färbung; bei brutpflegenden $\hat{o} \hat{o}$ wird diese durch die bekannte Kopf- 
maske - gelbe Wangen und Kehle, roter Kiemendeckelrand - ergänzt. (2) Dominanztracht: Außerhalb der Höhle ist ein dominantes Tier relativ hell gefärbr; der Kopf ist dann an der Seite graublau mit braunroten Flecken gezeichnet; auf dem Körper dominieren auf braunem Untergrund 3 schmale, in Wellenlinien verlaufende blaue Längsstreifen, über und zwischen diesen befinden sich große braunrote Flecken. Pectoralia und Analis erscheinen bläulich, letztere mit breitem blauschwarzen Saum; die Dorsalis ist dagegen nur blau gepunktet, die Caudalis ist gelb. (3) Subdominanztracht: Bei Tie-

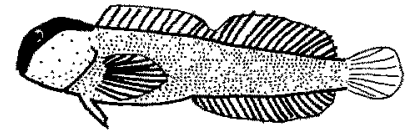

b
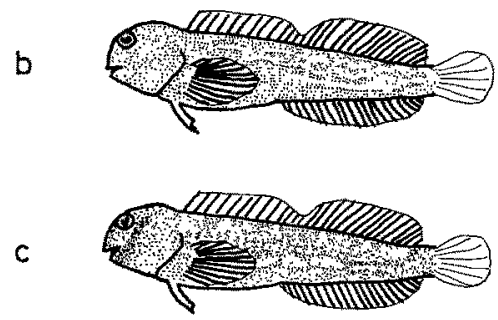

Abb. 17: Blennius canevae. $a$ Balz-/Besitztracht, $b$ Dominanztracht, $c$ Subdominanztracht

ren, die in der Rangfolge unter einem dominierenden stehen, erscheinen entlang der Rückenlinie 6 deutlich weiße Markierungen, die die Form eines umgekehrten $Y$ besitzen. Sie zeigen ferner in der Mittellinie einen unterbrochenen weißen Längsstreifen, darüber und darunter die eben erwähnten wellenförmigen blauen Längslinien. Der übrige Körper ist außer am silbrigen Bauch schokoladenbraun gefärbt; der Kopf weist dunkelbraune Punkte und 2 schwarzbraune Querbänder auf: Das 1. führt über den Scheitel, das 2. vom hinteren Augenrand zum Mundwinkel. Diese Färbung entspricht sehr wahrscheinlich der Weibchentracht ABELs (1964). (4) Umherstreiftracht: Bei umherstreifenden Tieren wird eine Zeichnung gezeigt, die zwischen Dominanz- und Rezessivtracht liegt. Die weiße mittlere Linie ist dann nur undeutlich vorhanden, am graubraunen Kopf sind nur rotbraune Flecken, aber keine Querstreifen zu erkennen. Darüber hinaus kann die Grundfärbung an die Farbe des jeweiligen Substrats angepaßt werden. Daher sind auch schwarze, dunkellila (auf Diatomeenbewuchs), olivgrüne oder rostrote (auf Hymeniacodon sanguined) Tiere beobachtet worden.

Da B. canevae im Brandungsbereich lebt, sind die Flossen, besonders Analis, Ventralia und die 3 unteren Strahlen der Pectoralia als Klammerorgane ausgebildet (Zander 1972a) (Abb.16c, d). Eine dicke Cuticula ist an denjenigen Teilen der genannten Flossen vorhanden, die mit dem Substrat in Berührung kommen. Der Körper ist gegeniiber $B$. spbinx mehr kompreß gestaltet und ähnelt in dieser Hinsicht $B$. incognitus, so daß $B$. canevae dem Leben im Brandungsbereich nicht besonders gut angepaßt erscheint. Sehr reduziert ist das Seitenorgansystem: Am Kopf ist je ein einfacher Orbital- und Präoperkularring vorhanden, im Posttemporalbereich befinden 
sich nur wenige Poren. Die Seitenlinie endet in Höhe der Pectoralia-Spitze und besitzt nur im vorderen Abschnitt einige Poren (Abb, 16c).

Als morphologische Besonderheit wurde ein Hautblutgefäß am Körper hinter dem Ansatz der Pectoralia und von dieser verdeckt gefunden. Welche funktionelle Bedeutung dieses hat, kann nicht entschieden werden. Weitere Angaben zur Morphologie dieser Art sind besonders der Originalbeschreibung von VINCIGUERRA (1880) zu entnehmen.

Auffallend waren bei den $\delta \partial$ dieser Art die vielen Flossenverletzungen, die offenbar auf Beißereien bei Rangordnungs- und Höhlenbesitzkämpfen zurückzuführen sind.

\section{Blennius dalmatinus STEINDACHNER \& Kolombatovic}

B. dalmatinus ist die kleinste Art dieser Gattung, da er nur knapp $4 \mathrm{~cm}$ groß ist. Er kommt im oberen Felslitoral ab $30 \mathrm{~cm}$ Wassertiefe vor, meidet allerdings der Brandung ausgesetzte Biotope. In Fundstellen, die vollkommen ungeschützt liegen wie Berard $(=8)$ oder Kristel $(=9)$, fehlt diese Art, in anderen, wie z. B. Kelibia (=4) hielt sie sich an Felsen auf, die durch andere seewärts vor der Brandung geschützt waren. In Banyuls ( $=13-18$ ), wo oft schwere Stürme herrschen, kommt sie nicht höher als $60 \mathrm{~cm}$ unter der Wasseroberfläche vor und wurde häufig zwischen 1 und $1,5 \mathrm{~m}$ gefunden; als größte Tiefe wurde bisher $2,5 \mathrm{~m}$ gemessen. Als Lebensraum bevorzugt werden horizontal oder etwas geneigt liegende weiße Felsen oder Plateaus, die nur mit kurzen Cladophora-Fäden und höchstens vereinzelt mit kurzen Thalli von Palmopbyl$l u m$ bewachsen sind. Typisch für dieses Habitat sind Arbacia livida und Balanus perforatus, deren leere Gehäuse neben Bohrmuschellöchern von $B$. dalmatinus als Wohnhöhlen aufgesucht werden. Die Besiedlung war stets locker, da auf einer $4 \mathrm{~m}^{2}$ großen Fläche nur 2 Brutpflege treibende $\delta \hat{\delta}$ neben einigen herumstreifenden $\not \circ q$ gefunden wurden. Eventuell ist diese Art photophil, da sie sich meist an besonnten, selten an schattigen Stellen aufhielt. Uberraschenderweise geht diese Art auch in brackiges Wasser, da sie von J. Parzefall im Basin de Thau bei Meze/Südfrankreich zusammen mit $B$. pavo gefangen wurde (Salzgehalt: $24 \% 0$ ).

Die $\$ ㅇ$ suchen nur auf der Flucht Löcher im Gestein auf, während Brutpflege treibende $\hat{o} \hat{o}$ nur sehr schwer aus ihren Höhlen zu vertreiben sind, da sie sich bei Störung in ihren meist geräumigen Hinterabschnitt zurückziehen. Die Fluchtdistanz ist gering. Die lochbewohnenden $\hat{\theta} \hat{o}$ sind zur Fortpflanzungszeit sehr auffallend gefärbt: Sie besitzen wie $B$. canevae- $\not \hat{\delta}$ dann einen schwarzen Scheitel, ihr Vorderkörper samt Kopf ist jedoch leuchtend zitronengelb gefärbt. Der schwarze Scheitel reicht bis zum Kopfende und setzt sich bis zum Ansatz der Dorsalis in Grautönen fort. Die 1. Querbinde, die nur auf der oberen Körperhälfte manifestiert ist, sowie die bis zur Ventralseite reichenden 2. und 3. Querbinden sind ebenfalls tiefschwarz, während die darauffolgenden grau erscheinen und nach caudal zu immer undeutlicher werden. Alle Querbinden sind hell irisierend eingefaßt. Der Hinterkörper zeigt bei diesen $\delta \hat{\delta}$ nur schwach gelbliche Grundfärbung. Die vordere Dorsalis ist deutlich gelb mit einem grauen Längsband im oberen Drittel gezeichnet, während der hintere Abschnitt nur einen gelben Saum aufweist. Die gelbe Analis besitzt dagegen einen schwärzlichen Saum. Ventralia 
und untere Pectoralia-Strahlen fallen durch ihre kräftige orangerote Färbung auf. Die Färbung der $\hat{\delta} \hat{\delta}$ außerhalb der Fortpflanzungszeit und der $q Q+$ ist hinsichtlich des Querstreifenmusters sehr variabel, wie bereits von BATH (1969) und ZANDER (1969) berichtet wurde. Die Grundfärbung ist bei diesen Tieren weißgrau bis milchigweiß.

B. dalmatinus ist sehr langgestreckt und kompreß gestaltet. Seine in Häkchen auslaufenden Flossenstrahlen der Pectoralia und Analis sowie die beiden Teilflossen der Ventralia sind nicht besonders krättig (Abb. 16e, f). Daher wären schon vom Körperbau her gesehen nicht die Voraussetzungen für ein Leben in der Brandungszone gegeben. Die Cuticula der äußeren Ventralteilflosse wird allerdings relativ dick manifestiert, während sie an der Analis und den unteren Pectoralia-Strahlen schwächer ausgebildet ist. Das Kopfkanal-/Seitenliniensystem ist stark reduziert. Es werden nur wenige Poren in dem einreihigen Orbital- oder Praeopercularring sowie in der Posttemporalregion ausgebildet. Die Seitenlinie selbst, die mehrfach unterbrochen nicht ganz um die Pectoralia herumführt, weist keine Poren auf (Abb. 16e).

\section{Blennius galerita $\mathrm{L}$.}

B. galerita ist als gelegentlicher Bewohner des Supralitorals wohl die interessanteste Form unter den hier behandelten Arten. Er ist fast immer knapp über oder unter der Wasseroberfläche zu finden, wo er auf dem freien Felsen liegt oder sich in flache Mulden preßt. Bevorzugt wird Fels ohne Algenaufwuchs, doch wird er auch auf Gestein, das stark mit Mytilus besetzt ist $(20=$ Tarragona), gefunden. Meistens halten sich die Tiere an der Brandung ausgesetzten Stellen auf, an denen sie zeitweilig trocken liegen und nur gelegentlich vom Wasser benetzt werden. An das Licht werden keine Ansprüche gestellt, da sie sowohl an sonnigen als auch an schattigen Biotopen vorkommen. Oft wurden sie in Kopf-Schwanz-Berührung kreisförmig gebogen auf dem Gestein ruhend gefunden, auch eine S-förmig gekrümmte Stellung war häufig zu beobachten (Abb. 18). Die Fluchtdistanz ist relativ groß, der Fluchtweg führte stets mit einem seitlichen Ausweichen nach oben über die Wasseroberfläche, wo dann flache Mulden mit geringem Sichtschutz aufgesucht werden; die Tiere sind dort allerdings mit ihrer dem wechselnden Substrat angepaßten Zeichnung gut getarnt. Die Umfärbung kann sehr schnell erfolgen und weist eine erstaunliche Zahl von Möglichkeiten auf: Die Grundfärbung kann das bekannte Braunschwarz aufweisen, aber auch in Rot, Rosa, Grün, Gelb oder Grau umschlagen; dabei kann die typische Marmorierung erhalten bleiben oder verschwinden. Kenntlich ist $B$. galerita dann stets an der gelblichweißen Oberlippe, die sich nicht verändert.

VoN HAcht konnte in Dramont $(=19)$ beobachten, daß sich die Tiere nachts nahezu inaktiv bis $40 \mathrm{~cm}$ oberhalb der Wasserlinie aufhalten. Dort werden sie nur noch von etwa jeder 6. Welle überspült; dann kann zwar die Lage des hinteren Körperabschnittes verändert werden, aber nicht der vordere, der infolge der Verklammerung mit den Flossen unbeweglich bleibt. Die Reaktionen sind zu dieser Zeit äußerst gering; erst nach mehreren Minuten erfolgen gegenüber Fangversuchen oder dem Lampenschein Fluchtbewegungen in Richtung Wasser, so daß bei diesem Verhalten von einem „Schlafen" gesprochen werden kann. Schnelle Reaktionen erfolgen nur bei Be- 
rührung durch Extremitäten von Krabben (Pachygrapsus), die eine sofortige Flucht zur Folge hat. Offenbar sind diese Crustaceen die hauptsächlichen Feinde dieser Fische außerhalb des Wassers. Die Atemfrequenz ist an Land auf unter 60/Minute, also etwa der Hälfte des Wertes unter Wasser herabgesetzt.

Tagsüber konnten bisher keine Aktivitäten an Land festgestellt werden, nachdem Soljan (1932) die Nahrungsaufnahme dieser Art in der Spritzzone beschrieben hatte.
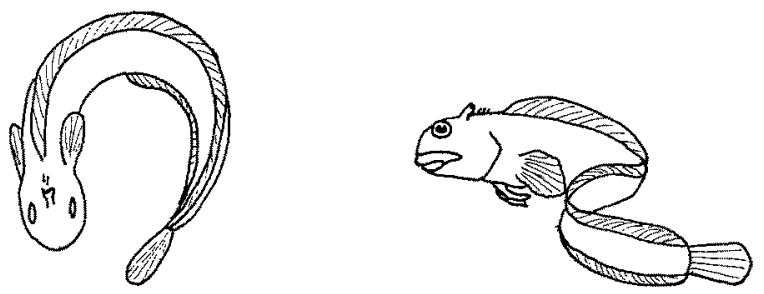

Abb. 18: Ruhestellungen von Blennius galerita am abfallenden Felsen

Die Laichzeit ist noch nicht eindeutig festzulegen. Nach Beobachtungen in Tarragona $(=20)$ schien die Fortpflanzung am 12.5.1971 in vollem Gange zu sein, da die $\delta \hat{\delta}$ dunkel-braunschwarz gefärbt waren und sich nur ihre weiße Oberlippe („Negerlippe“, ABEL 1964) deutlich abhob. Solche ô $\delta$ saßen in tiefen Mulden zwischen Miesmuscheln am senkrechten oder stark geneigten Felsen. Es wurde dort ferner beobachtet, daß $q 9+$, kenntlich an dem geschwollenen Bauch, mit jeweils einem $\hat{o}$ zusammen und dicht an dieses geschmiegt in solch einer Mulde saßen und offenbar ablaichten. Andere 우 mit deutlicher Querbänderung streiften auf den Felsen umher. - $\mathrm{Zu}$ den anderen Beobachtungszeiten - Juli in Banyuls, August bis September an der nordafrikanischen und spanischen Küste - war keine Fortpflanzungsaktivität zu erkennen.

An morphologischen Besonderheiten findet man am Kopf von B. galerita besonder's in der postorbitalen Region an die Hautoberfläche tretende Blutgefäße, die offenbar in den Dienst der zusätzlichen Atmung an Land treten können (Abb. 16g). Solche Hautblutgefäße wurden bereits bei amphibisch lebenden Blenniidae des Roten Meeres (Alticus kirkii, Istiblennius edentulus und I. flaviumbrinus) entdeckt (ZANDER 1972c). Alle Analis- und die 5 unteren Pectoralia-Strahlen, die in Häkchen enden, sind zu sehr kräftigen Klammerorganen entwickelt (ZANDER 1972a). Die Ventralia sind zu 2 kurzen, aber relativ breiten Flossenarmen entwickelt, die an ihrer Basis jeweils weit voneinander getrennt sind (Abb, 16g, h). Die Cuticula ist an den genannten Flossen sehr stark entwickelt. Das Kopfkanalsystem ist durch einen einfachen Orbital- und Präopercularring ausgezeichnet, während die Seitenlinie sehr reduziert erscheint und ohne Seitenkanälchen nur bis zur Höhe der letzten ungegliederten Dorsalis-Strahlen führt; es führen dort nur wenige Poren nach außen (Abb. 16g). Diese Art zeichnet sich wie B. cristatus und $B$. trigloides durch eine leicht depresse, an der Ventralseite breite Körpergestalt aus, die eine Anpassung an das Leben in der Brandungszone darstellt. Weitere Besonderheiten dieser Art sind die vielen Kopftentakel, deren vorderster lappenförmig gestaltet ist, sowie die reichliche Bezahnung, bei der aber Edkzähne fehlen. 


\section{Der Einfluß ökologischer Faktoren auf die horizontale und vertikale Verbreitung der Blennius-Arten}

Zum Schluß soll an Hand der wichtigsten ökologischen Faktoren ein allgemeines Verbreitungsbild der untersuchten Blennius-Arten herausgearbeitet werden. Es wird in diesem Zusammenhang noch einmal auf die grundlegende Arbeit ABELs (1962) verwiesen, die hier mit weiteren Tatsachen und der Behandlung weiterer Arten ergänzt wird.

\section{Temperatur}

Die mittlere Jahrestemperatur spielt für das geographische Verbreitungsbild eine entscheidende Rolle. Nach EKMAN (1953) zerfällt das Mittelmeer klimatisch in das kältere westliche und das wärmere östliche Becken. Besonders der nordwestliche Bereich dieses Meeres scheint klimatisch ungünstiger zu liegen als der übrige Teil, von dem der südöstliche Bereich am wärmsten ist. Arten, die in diesen beiden extremen Gebieten vorkommen, müssen als eurytherm angesehen werden. Dazu würden $B$. sphinx, B. canevae, $B$. incognitus, $B$. pavo und $B$. sanguinolentus gehören, unter der Berücksichtigung der Funde in Israel auch B. galerita, B. trigloides, B. gattorugine (STernIrz 1950) und $B$. zvonimiri (HeYmer in litt.). Auch die z. T'. recht beträchtlichen Tagesschwankungen der Temperatur werden von diesen Arten ohne Schwierigkeiten vertragen; so wurde z. B. in Salakta $(=1)$ morgens eine Wassertemperatur von $24^{\circ}$ festgestellt, die im Laufe des Vormittags auf $30^{\circ} \mathrm{C}$ anstieg. Die gleichen Blennius-Arten, die an diesem Fundort beobachtet wurden, kommen andererseits auch in Banyuls (13-18) vor, wo die Höchsttemperatur im Juli nicht über $20^{\circ} \mathrm{C}$ stieg. In den wärmeren Bereichen des Mittelmeeres fehlt dagegen $B$. dalmatinus, während B. cristatus in dem kälteren Abschnitt nicht gefunden wird. Unklar sind noch die Verhältnise bei $B$. vandervekeni, der nur an der marokkanischen, algerischen und südspanischen Küste beobachtet wurde. Da diese Art im Nord- und Südatlantik weit verbreitet ist, liegt die Vermutung nahe, daß es sich phylogenetisch gesehen um einen relativ späten Einwandeter in das Mittelmeer handelt, der sich dort nur langsam ausbreitet.

Das vertikale Temperaturgefälle spielt für die hier untersuchten Arten keine Rolle, da sie in einem Bereich leben, in dem eine gute Durchmischung verschieden temperierter Schichten gegeben ist.

\section{Licht}

Die Bedeutung des Lichtfaktors für die Verteilung der Blenniidae wurde bereits von ABEL (1962) herausgestellt. Dieser Autor stufte $B$. sphinx, B. sanguinolentus und $B$. rouxi als photophil ein, während $B$. gattorugine und $B$. zvonimiri als schattenliebend bezeichnet wurden und $B$. nigriceps sich eindeutig als Höhlenbewohner erwies. Keine Lichtansprüche stellen hingegen $B$. galerita, $B$. trigloides, $B$. canevae und $B$. incognitus. Die eigenen Ergebnise, die in Tabelle 2 dargestellt sind, können diese Befunde im allgemeinen bestätigen. Etwas kompliziert sind die Verhältnise bei $B$. gattorugine, weil die Jungfische durchaus an der Sonne ausgesetzten Biotopen angetroffen wurden, wäh- 
Tabelle 1

Vorkommen von 12 Blennius-Arten des oberen Litorals hinsichtlich der Lichteinwirkung. $+=$ sonnig, $-=$ schattig, $O=$ lichtarm

\begin{tabular}{|c|c|c|c|c|c|c|c|c|c|c|c|c|c|c|c|c|c|}
\hline Biotop & 1 & 2 & 3 & 4 & 5 & 6 & 7 & 8 & 9 & 10 & 11 & 12 & 13 & 14 & 18 & 19 & 20 \\
\hline B. galerita & & & & - & & & - & - & + & & \pm & + & & - & & + & + \\
\hline B. trigloides & & & & & & 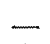 & - & - & + & & \pm & + & & - & - & & \pm \\
\hline B. sphinx & + & + & & + & + & + & + & + & + & + & + & + & + & + & + & & $T$ \\
\hline B. cristatus & & & & & & \pm & & \pm & + & & & + & & & & & \\
\hline $\begin{array}{l}\text { B. canevale } \\
\text { B. gattorugine }\end{array}$ & & 0 & & & - & - & - & - & + & & - & + & \pm & \pm & - & & - \\
\hline $\begin{array}{l}B . \text { incognitus } \\
B . \text { zvonimiri }\end{array}$ & - & + & & - & + & + & + & + & & & + & + & + & \pm & $\stackrel{+}{\circ}$ & & + \\
\hline $\begin{array}{l}\text { B. vandervekeni } \\
\text { B. pavo }\end{array}$ & & & + & + & & \pm & - & + & \pm & & - & + & + & & & & \\
\hline $\begin{array}{l}\text { B. palo } \\
\text { B. dalmatinus }\end{array}$ & & & + & + & + & $\bar{t}$ & & & & & & + & & + & + & & + \\
\hline $\begin{array}{l}\text { B. sanguino- } \\
\text { lentus }\end{array}$ & + & + & & + & + & + & + & & & + & + & + & & + & + & & + \\
\hline
\end{tabular}

rend für die Adulten die Angabe Abels bestätigt werden kann. Auch B. zvonimiri hält sich keineswegs nur an schattigen Stellen auf, da - wie oben beschrieben - die Versteckplätze dieser Art im extrem lichtarmen oder sogar Höhlenbereich liegen.

Die nicht von ABEL untersuchten Arten B. pavo und B. dalmatinus sind sehr wahrscheinlich als photophil einzustufen, nur einmal wurde $B$. pavo in einem schattigen Habitat beobachtet (Tab. 1). Dagegen stellen $B$. cristatus und $B$. vandervekeni keine besonderen Lichtansprïche. Das Licht kann somit als ein wichtiger Faktor für die Differenzierung der Blennius-Arten betrachtet werden.

\section{Salzgebalt}

Aus der Tatsache, daß die besprochenen Blennius-Arten im oberen Litoralbereich leben, ergibt sich eine gewisse Toleranz gegenüber Salzgehaltsschwankungen. Bei starken Regengüssen kommt es zur Aussüßung der oberen Wasserschichten, andererseits führt längere intensive Sonneneinstrahlung infolge der Wasserverdunstung zu einem Ansteigen der Salzkonzentration. Dieser Wechsel wird von allen Arten ohne Beeinträchtigung ertragen. Als extrem euryhalin erwiesen sich dagegen nur B. pavo und B. dalmatinus, die auch noch in Brackwasser von $22 \%$ (Salses) bzw. 24\% (Meze) ihre normale Aktivität entfalten, während der dort noch ebenfalls vorkommende $B$. sphinx nach seinem Verhalten zu urteilen nicht seine optimalen Lebensbedingungen findet (J. Parzefall, mündlich).

\section{Wasserbewegung}

Wie in einer anderen Arbeit dargestellt wurde (ZANDER 1972a), ist die Tiefenverbreitung der Blenniws-Arten mit der Stärke der Wasserbewegung korreliert. An einem der offenen See ausgerichteten Felsen kommen B. galerita, B. trigloides, B. sphinx, 
$B$. cristatus und auch noch $B$. canevae in der oberen, der Brandung ausgesetzten Zone vor, während $B$. gattorugine, $B$. incognitus, $B$. vandervekeni, $B$. dalmatinus und $B$. sanguinolentus in dem stets mit Wasser bedeckten, tieferen Turbulenzbereich leben. In 2 Meter Wassertiefe werden meistens nur noch ruhigere Strömungen festgestellt, die gleichgerichtet verlaufen; von dieser Grenze an wird z. B. der hier nicht näher besprochene B. rouxi angetroffen. Wie aus Tabelle 3 hervorgeht, gibt es bei den Arten, die im Brandungsbereich leben, keine Unterschiede hinsichtlich ihrer Mindest-Aufenthaltstiefe bei Vorkommen an geschützten, weniger geschützten oder ungeschützten Biotopen; dieses ist besonders gut am Beispiel von $B$. sphinx oder $B$. canevae zu erkennen. Typische Vertreter des Turbulenzbereiches hingegen werden an geschützten Stellen sehr viel näher zur Wasseroberfläche angetroffen als an ungeschützten; als Beispiele seien hier B. gattorugine, B. incognitus und B. dalmatinus angefuhrt (Tab. 2). Aus der Ta-

Tabelle 2

Abhängigkeit der Tiefenverbreitung von 12 Blennius-Arten von der Wasserbewegung. Die Zahlen bedeuten die festgestellte Mindesttiefe in $\mathrm{cm}$ unter der Wasseroberfläche, Vorkommen über die Wasserlinie ist mir + gekennzeichnet. Die Symbole bedeuten: $G=$ Biotop geschützt, $M=$ Biotop geschützt, aber mittelstarker Wellenbewegung ausgesetzt, $U=$ Biotop ungeschützt, der vollen Brandung ausgesetzt

\begin{tabular}{|c|c|c|c|c|c|c|c|c|c|c|c|c|c|c|c|c|c|}
\hline Biotop & 1 & 2 & 3 & 4 & 5 & 6 & 7 & 8 & 9 & 10 & 11 & 12 & 13 & 14 & 18 & 19 & 20 \\
\hline B. galerita & $\begin{array}{l}M \\
U\end{array}$ & & & 0 & & & to & 0 & 20 & & 0 & +20 & & 0 & & +40 & +20 \\
\hline B. trigloides & $\underset{U}{M}$ & & & & & 0 & +o & 0 & 20 & & 0 & 0 & & 0 & 10 & & 0 \\
\hline B. spbin $x$ & $\begin{array}{l}\mathrm{G} 10 \\
\mathrm{M} \\
\mathrm{U}\end{array}$ & 20 & & 10 & 20 & 20 & 10 & 20 & 20 & 20 & 10 & $\begin{array}{l}20 \\
20\end{array}$ & 20 & $\begin{array}{l}20 \\
40\end{array}$ & 20 & & $\begin{array}{l}20 \\
40\end{array}$ \\
\hline B. cristatus & $\begin{array}{l}\mathrm{M} \\
\mathrm{U}\end{array}$ & & & & & 0 & & 10 & 20 & & & 20 & & & & & \\
\hline$B$. canevae & $\begin{array}{l}\mathrm{G} \\
\mathrm{M} \\
\mathrm{U}\end{array}$ & 20 & & & & 10 & & 20 & 20 & & 20 & 20 & 20 & $\begin{array}{l}10 \\
10\end{array}$ & 30 & & 40 \\
\hline $\begin{array}{l}\text { B. gattorn- } \\
\text { gine }\end{array}$ & $\begin{array}{l}\mathrm{G} \\
\mathrm{M} \\
\mathrm{U}\end{array}$ & & & & 100 & & 30 & & & & 50 & & 30 & 100 & 150 & & 100 \\
\hline B. incognitus & $\begin{array}{l}\mathrm{G} 30 \\
\mathrm{M} \\
\mathrm{U}\end{array}$ & 80 & & 30 & 40 & 30 & 30 & 50 & & & 30 & $\begin{array}{l}40 \\
50\end{array}$ & 20 & 70 & & & $\begin{array}{l}20 \\
50\end{array}$ \\
\hline B. zvonimiri & G & & & & & & & & & & & & 100 & & 50 & & \\
\hline $\begin{array}{l}\text { B. vander- } \\
\text { vekeni }\end{array}$ & $\begin{array}{l}\mathrm{G} \\
\mathrm{M} \\
\mathrm{U}\end{array}$ & & & & & 20 & 50 & 50 & 50 & & 50 & & & & & & \\
\hline B. pavo & G & & 40 & 20 & & 30 & & & & & & 50 & 10 & & & & \\
\hline $\begin{array}{l}\text { B. dalmati- } \\
\text { nus }\end{array}$ & $\begin{array}{l}G \\
U\end{array}$ & & & 30 & 20 & 30 & & & & & & 50 & & 60 & 80 & & 20 \\
\hline $\begin{array}{l}\text { B. sanguino- } \\
\text { lentus }\end{array}$ & $\begin{array}{l}G 60 \\
\stackrel{M}{U}\end{array}$ & $\begin{array}{r}30 \\
100\end{array}$ & & 40 & 60 & 20 & 60 & & & 40 & 90 & 50 & & 30 & 50 & 150 & 50 \\
\hline
\end{tabular}


Ókologie und Biologie von Blenniidae

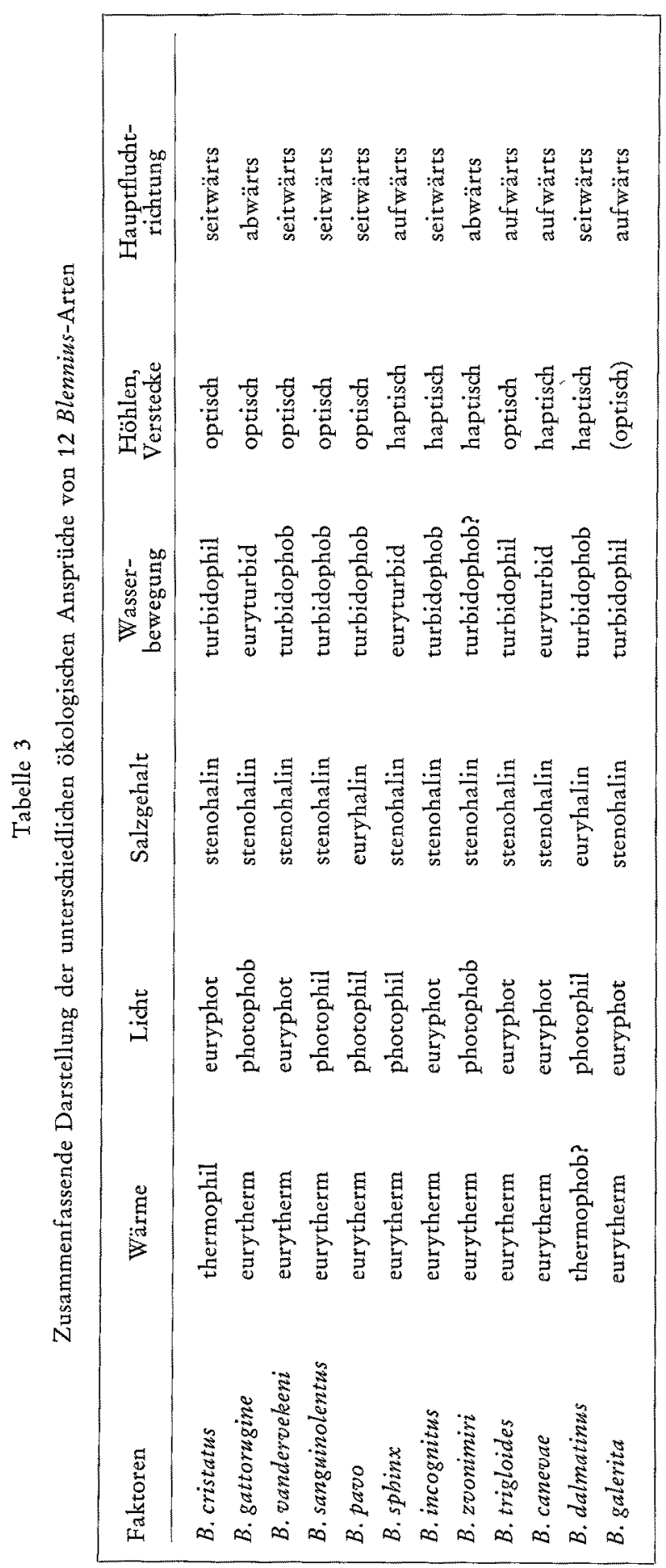


belle 3 ist ferner eine Spezialisierung für ruhige oder bewegte Biotope bei einigen Arten erkennbar. Während $B$. galerita, $B$. trigloides und $B$. cristatus nicht an geschützten Stellen beobachtet wurden, meidet $B$. pavo offenbar Biotope mit bewegtem Wasser. Die anderen Arten müssen in dieser Hinsicht als eurypotent angesehen werden; nur über $B$. zvonimiri können noch keine Aussagen gemacht werden, da zu wenige Funde vorliegen.

Auffallend ist die Korrelation der körperbaulichen Anpassungen an die eben geschilderten Verhältnisse. Ein runder, leicht depresser Körper ist bei den Arten B. galerita, $B$. trigloides, $B$. sphinx und $B$. cristatus, die in der Brandungszone leben, typisch, während die übrigen Arten mehr kompreß gestaltet sind. Erstere sind dadurch, daß sie dem Substrat mit breiterer Fläche aufliegen, vor dem Abschwemmen durch Brandungswellen geschützter als letztere. Der Aufenthalt von $B$. canevae in der Brandungszone kann trotz kompresser Körpergestalt dadurch ermöglicht werden, daß diese Art ständige Wohnhộhlen besitzt, in die sie sich bei ungünstiger Wetterlage verbergen kann.

Ferner sind die Flossenstrahlen der Arten des Brandungsbereiches als starke Klammerorgane ausgebildet, die sich in Gestalt von Häkchen in dem Substrat verankern können. Bei den übrigen Arten, außer B. gattorugine, sind diese schwächer gestaltet und erzielen daher nicht die gleiche Wirksamkeit (ZaNDER 1972a). Die Manifestation des Seitenorgansystems steht dagegen in keinem Zusammenhang mit der Lebensweise in Zonen mit unterschiedlicher Wasserbewegung. Bis auf $B$. cristatus und $B$. trigloides zeigen die übrigen Arten der Brandungszone einfache ( $B . \operatorname{sphinx}$ ) oder reduzierte Organsysteme ( $B$. canevae und $B$. galerita). Daher wird vermutet, daß es sich bei $B$. cristatus, der die am höchsten entwickelten Seitenorgane besitzt, um eine ursprüngliche Form handelt, von der sich möglicherweise die übrigen Arten ableiten lassen (ZANDER 1972b). In der weiteren phylogenetischen Entwicklung kam es dann beim Übergang zur demersen Lebensweise zur Reduzierung der Seitenorgane, so daß bei einer sekundären Eroberung des Brandungsbereiches $z$. B. der abgeleitete B. galerita zusammen mit dem ursprünglichen $B$. cristatus lebt.

\section{Versteckplätze}

In Hinsicht auf die Versteckplätze sollen nur die Angaben ABELs (1962) mit den Befunden der Arten B. cristatus, $B$. vandervekeni, $B$. pavo und $B$. dalmatinus ergänzt werden, die jener Autor nicht berücksichtigt hatte. Von diesen suchen die drei erstgenannten Arten optische, $B$. dalmatinus aber haptische Höhlen auf. B. sphinx, der nur zur Laichzeit haptische Höhlen besetzt, versteckt sich gelegentlich bei Gefahr zwischen Algenbüscheln, meistens entzieht er sich Verfolgern jedoch durch Flucht über die Wasserlinie. Die gleiche Fluchtrichtung war auch bei $B$. galerita, $B$. trigloides, $B$. canevae und gelegentlich bei $B$. cristatus und $B$. sanguinolentus $\mathrm{zu}$ beobachten. Bemerkenswert ist, daß $B$. galerita keine Höhlen, sondern höchstens flache Mulden mit geringem Sichtschutz aufsucht, dort aber durch Farbanpassung an den Untergrund leicht übersehen wird. Die Fluchtrichtung von $B$. zvonimiri und $B$. gattorugine führt demgegenüber in tiefere Wasserschichten. 


\section{SCHLUSSBEMERKUNG}

Die Untersuchungen dieser Arbeit ergänzen und erweitern die Ergebnisse ABELs (1962, 1964) durch die Einbeziehung von 4 weiteren Arten (B. cristatus, $B$. vandervekeni, $B$. pavo und $B$. dalmatinus) und die Behandlung weiterer ökologischer Faktoren. In Tabelle 3 wurden diese in Beziehung zu den jeweiligen Ansprüchen der hier behandelten 12 Blennius-Arten gesetzt. (Auf die Tiefenverbreitung wurde dort verzichtet, da diese von anderen Faktoren abhängt: Tabelle 2.)

Es wird festgestellt, daß die Vielfalt der geschilderten ökologischen Faktoren und deren Kombinationsmöglichkeiten die Schaffung verschiedenster Mirkoklimate und Okotope ermöglichte, die von bestimmten Blenniws-Arten erobert wurden (Tab. 3), und letzten Endes den Artenreichtum dieser Gattung während ihrer Evolution ermöglichte. Unter ihnen gibt es eine Reihe von Arten, die als Zwillingsarten angesprochen werden können, da sie morphologisch schwer zu unterscheiden sind, z. B. Blennius incognitus und $B$. zvonimiri, $B$. adriaticus und $B$. dalmatinus, $B$. canevae und $B$. nigriceps. Es ist anzunehmen, daß ihre morphologische Differenzierung erst dann erfolgen konnte, als sie infolge der Besiedlung verschiedener ökologischer Nischen und daraufhin auftretender Verhaltensbarrieren fortpflanzungsmäßig isoliert wurden.

\section{ZUSAMMENFASSUNG}

1. An insgesamt 20 Fundstellen des südlichen und westlichen Mittelmeeres (Abb. 1) wurden ökologische und biologische Untersuchungen bis ca. 1,5 m unter die Wasserlinie vorgenommen, die besonders Schleimfische der Gattung Blennius betrafen. 8 der Fundstellen wurden genauer beschrieben und in Profilen dargestellt. Insgesamt konnten 12 Blennius-Arten in die Untersuchungen einbezogen werden.

2. Nachdem Abel (1962) Angaben über die Tiefenverbreitung und die Licht- und Wohnraumansprüche von 10 Blennius-Arten gemacht hatte, wurden hier 4 weitere Arten und weitere ökologische Faktoren berücksichtigt.

3. Auf Grund des Verbreitungsbildes wird B. cristatus als thermophil, B. dalmatinus als eventuell thermophob bezeichnet, während alle übrigen Arten als eurytherm anzusprechen sind.

4. In bezug auf die Lichtansprüche stellten sich 4 Arten - B. sanguinolentus, B. pavo, $B$. sphinx und $B$. dalmatinus - als photophil, $B$. gattorugine und $B$. zvonimiri aber als photophob heraus. Die übrigen Arten stellen dagegen keine Lichtansprüche.

5. Nur B. pavo und B. dalmatinus erwiesen sich als euryhaline Arten, die auch im Brackwasser zu finden sind.

6. Typische Bewohner der Brandungszone sind $B$. galerita, B. trigloides und $B$. cristatus, während $B . \operatorname{sphinx}, B$. canevae und $B$. gattorugine als fakultative Besiedler dieses Bereichs anzusehen sind. Alle übrigen Arten meiden in mehr oder weniger ausgeprägtem Maße die Brandungszone, indem sie entweder in tiefere Wasserschichten oder an geschützte Stellen ausweichen. Die Tiefenverbreitung hängt daher weitgehend von dem Faktor Wasserbewegung ab und ist mindestens in ihrer oberen Grenze bei den turbidophoben Arten nicht eindeutig festlegbar. 
7. Die Hauptfluchtrichtung steht einerseits mit der Bevorzugung verschieden starker Turbulenzen zusammen. So fliehen B. galerita, B. trigloides, B. sphinx und B. canevae aufwärts, während die meisten übrigen Arten bei Gefahr seitwärts ausweichen. Andererseits resultiert die abwärts gerichtete Flucht von $B$. gattorugine und B. zvonimiri aus der Bevorzugung lichtarmer Ókotope.

8. Als morphologische Anpassungen an die durch Wasserbewegung beeinflußten Okotope konnte die Körpergestalt - rund bis depreß bei den Bewohnern des Brandungsbereiches, kompreß bei den übrigen Arten - und die unterschiedliche Stärke der Flossenstrahlen von Pectoralia, Ventralia und Analis festgestellt werden. Keine Korrelation zum Okotop besteht dagegen in der Ausbildung des Seitenorgansystems.

9. Außer B. galerita suchen alle ïbrigen 11 Arten mindestens zur Laichzeit Verstecke auf. $B$. cristatus, $B$. gattorugine, B. vandervekeni, $B$. sanguinolentus, $B$. pavo und $B$. trigloides suchen optische (sichtgeschützte) Höhlen auf, während die übrigen Arten enge, ihrem Körperdurchmesser entsprechende haptische Höhlen bevorzugen.

10. Bei einigen Arten wurden ergänzende Beobachtungen über das Balz- und Rivalenverhalten sowie über Färbung und Farbwechsel gemacht.

11. Es wird angenommen, daß die Schaffung verschiedener OKotope und Mikroklimate Voraussetzung für die Aufspaltung der Gattung Blennius in eine große Zahl verschiedener Arten war.

Danksagungen. Für Unterstützung und Hilfe beim. Fang der Fische während der Nordafrikareise 1968 möchte ich den Herren Dr. H. STRüMPEI und Prof. W. VnLwwock sehr herzlich danken. Herrn Prof. P. DRACH, der mir am Laboratoire Arago in Banyuls-sur-Mer Gastrecht und jede Unterstützung gewährte, schließe ich in den Dank ein, ebenso die Herren H. G. ANDRES und Dr. A. HeYmer, die mir in Banyuls-sur-Mer beim Fang der Fische halfen, und Herrn

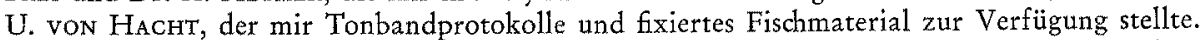
Schließlich gewährten die Deutsche Forschungsgemeinschaft und die B.A.T.-Stiftung Reisebeihilfen, für die ich hiermit danke.

\section{ZITIERTE LITERATUR}

Aвel, E. F., 1959. Zur Kenntnis der Beziehungen der Fische zu Höhlen im Mittelmeer. Pubbl. Staz. zool. Napoli (Suppl. Bd.) 30, 519-528.

- 1962. Freiwasserbeobachtungen an Fischen im Golf von Neapel als Beitrag zur Kenntnis ihrer Okologie und ihres Verhaltens. Int. Revue ges. Hydrobiol. 47, 219-290.

- 1964. Freiwasserstudien zur Fortpllanzungsethologie zweier Mittelmeerfische, Blennius cane-

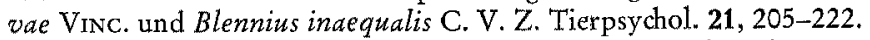

Bath, H., 1966. Erstmaliger Nachweis von Blennius vandervekeni Poll 1959 im Mittelmeer (Pisces, Blennioidea, Blenniidae). Senckenberg. biol. 47, 411-418.

- 1968. Untersuchung von Blennius zvonimiri Kolombatovic und Beschreibung von Blennius incognitus n. sp. aus dem Mittelmeer (Pisces, Blennioidea, Blenniidae). Senckenberg. biol. 49, 367-386.

- 1969. Zur Kenntnis des Schleimfisches Blennius dalmatinus SteIndachner 1883 und seiner Verbreitung im Mittelmeer (Pisces, Blennioidea, Blenniidae). Senckenberg. biol. 50, 97-102.

- 1970. Vergleichend-morphologische, taxonomische und zoogeographische Untersuchungen an den Schleimfischarten Blennius cristatus, crinitus und nucbifilis (Pisces: Blennioidea: Blenniidae). Sendkenberg. biol. 51, 287-306. 
- 1971. Zur Morphologie und Verbreitung von Blennius adriaticus STEINDAchNer \& KolomBatovic sowie kritische Bemerkungen über Blennius knipowitscbi SLASTENENKo (Pisces: Blennioidea : Blenniidae). Senckenberg. biol. 52, 17-29.

EgGERT, B., 1931. Die Geschlechtsorgane der Gobiiformes und Blenniiformes. Z. wiss. Zool. 139, 249-558.

EкMAN, S., 1953. Zoogeography of the sea. Sidgwick \& Jackson, London, 417 S.

GurTel, F., 1893. Observations sur les moeurs des trois blennides, Clinus argentatus, Blennius montagui, et Blennius sphinx. Archs. Zool. exp. gén. (Sér. 3) 1, 325-384.

Norman, J. R., 1943. Notes on the blennoid fishes. I. A provisional synopsis of the genera of the family Blenniidae. Ann. Mag. nat. Hist. 10, 793-812.

Poll, M., 1959. Poissons. V.-Téléostéens acanthoptérygiens, P. 2. Hayez, Brüssel, 416 S.

(Résult. scient. Expedition océanographique Belge dans les eaux côtières Africaines de I'Atlantique Sud [1948-1949]. Vol, 4, Fasc. 3 B.).

SolJAN, T., 1932. Blennins galerita L., poisson amphibien des zones supralittorale et littorale exposées de l'Adriatique. Acta adriat. 2, 1-14.

Sternitz, H., 1950. Contribution to the knowledge of the Blenniidae of the Eastern Mediterranean. III. Istanb. Üniv. Fen. Fak. Mecm. (B) 15, 60-87.

Vinciguerra, D., 1880. Appunti ittiologici sulle collezione del Museo Civico di Genova. III. Intorno ai Blennioidi del Golfo die Genova. Annali Mus. civ. Stor. nat. Giacomo Doria $15,430-453$.

Zander, C. D., 1969. Mitteilung über die Verbreitung und Okologie von Blennioidei des Mittelmeeres (Pisces). Mitt. hamb. zool. Mus. Inst. 66, 59-63.

- 1972a. Zur Morphologie der Flossen von Blenniidae (Pisces) des Mittelmeeres. Rapp. P.-v. Réun. Commn int. Explor. scient. Mer Méditerr. 22 (im Druck).

- 1972b. Zur Verbreitungsgeschichte der Gattung Blennius (Blennioidei, Pisces). Mitt. hamb. zool. Mus. Inst. 68, 213-230.

- 1972c. Beziehungen zwischen Körperbau und Lebensweise bei Blenniidae (Pisces) aus dem Roten Meer. I. Kußere Morphologie. Mar. Biol. 13, 238-246.

- \& Heymer, A., 1970. Tripterygion tripteronotus (Rrsso, 1810) und Tripterygion xanthosoma n. sp. (Pisces) - eine ökologische Speziation. Vie Milieu (A) 21, 363-394.

Anschrift des Autors: Dr. C. D. Zander

Zoologisches Institut und Zoologisches Museum

2 Hamburg 13

Papendamm 3

Bundesrepublik Deutschland 